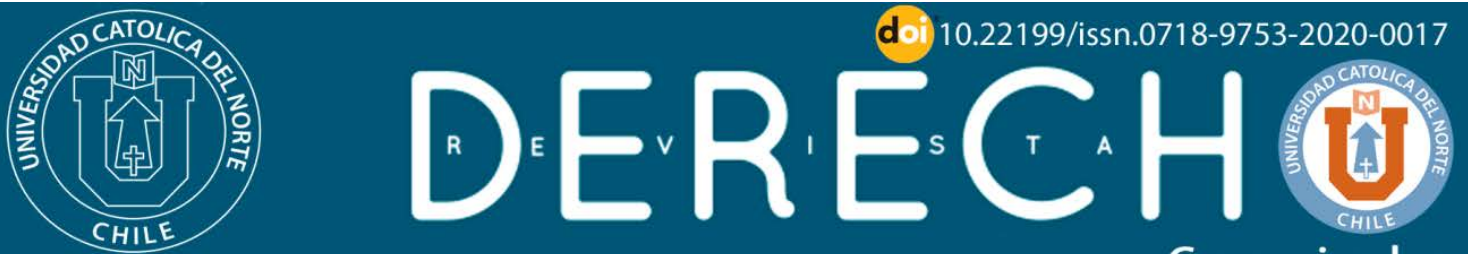

C O q u i m bo

REVISTAS CIENTIIFICAS

ISSN: 0718-9753 (En línea)

\title{
Empresas del Estado y su vinculación al Derecho Público Chileno en materia laboral
}

\section{State Companies and their connection to Chilean public law in labor matter}

\author{
Valeska Opazo de la Fuente' 1 (D) https://orcid.org/0000-0003-4178-9653 \\ ${ }^{1}$ Universidad Católica de la Santísima Concepción, Concepción, Chile. Profesora de Derecho Adminis- \\ trativo. Abogada. Doctora en Derecho, P. U. Católica de Chile. \\ @vaopazo@ucsc.cl \\ (cc) BY
}

\section{Resumen:}

Ante la autonomía de las empresas del Estado y su carácter mercantil, este trabajo tiene por objetivo sostener que tales organismos se encuentran condicionados a principios públicos en sus relaciones laborales, como forma de dar protección al interés público inserto en su funcionamiento, y sus trabajadores están regulados por un estatuto administrativo distinto al del sector estatal, que les permite disfrutar de derechos colectivos, no obstante su calidad de funcionarios públicos. En la primera parte, partiendo de que las empresas estatales pertenecen a la Administración Pública, el trabajo analiza las exigencias públicas que se les imponen, en su calidad de empleadoras, y la importancia de éstas para el resguardo de la comunidad. En la segunda parte la premisa se centra en el carácter público de sus trabajadores y su especial regulación, espacio desde el cual el artículo examina tres derechos en particular: la sindicalización, la negociación colectiva y la huelga. Concluye, respecto de las empresas, que el interés público envuelto en su gestión fundamenta un especial modo de funcionamiento en sus relaciones laborales, $y$ en lo pertinente a sus trabajadores, se establece que gozan de los derechos señalados. Palabras Clave: Administración Pública; Autonomía; Funcionarios Públicos; Estatuto Administrativo.

\begin{abstract}
:
Due to the autonomy of state companies and their commercial nature, this work aims to maintain that such organizations are conditioned on public principles in labor relations, as a way of giving protection to public interest that are inserted in their functionality, and their public servants are regulated by an administrative statute that is different from the rest of the government workers, that allows them to hold, in general, bargaining rights, regardless of their status as civil servants. In the first part, starting from that state companies belong to public administration, this work analyzes the public demands that are imposed on them as employers and the importance of these for the community protection. In the second part, the premise focuses on the public character of the workers and their special regulation, space from which the article examines three rights in particular: unionization, collective negotiation and strikes. It concludes, regarding the companies, that public interest involved in their management bases a special way of functioning in their labor relations, and regarding their workers, it is established that they hold the indicated rights.

Keywords: Public administration; Autonomy; Public servants; Public servants regulation.
\end{abstract}


Empresas del Estado y su vinculación al Derecho Público Chileno en materia laboral.

\section{Introducción}

En mayo de 2017 la Contraloría General de la República, por medio del Dictamen № 15759, se pronunció sobre las prestaciones económicas pagadas por la Corporación Nacional del Cobre a un ex director, que abarcaban, en su totalidad, más de 511 millones de pesos. Específicamente, le hizo presente a la empresa estatal su obligación de sujetarse a los principios de eficiencia, eficacia y probidad, y de dar preeminencia al interés general por sobre el particular. La cuprífera solicitó una reconsideración del dictamen, por estimar que éste restringía su autonomía en el ámbito de las relaciones laborales. Sin embargo, ésta fue rechazada a través del pronunciamiento No 18850 del mismo año.

¿Corresponde que las empresas del Estado -que para efectos prácticos se denominarán indistintamente empresas públicas o estatales, se hace presente que la utilización de tales expresiones es solo para efectos de redacción, ya que no se deben confundir los términos "empresas estatales", "sociedades del Estado" y "empresas del Estado", toda vez que la primera es comprensiva de las otras dos, Soto Kloss (2010, p. 216) -, gocen de la misma libertad que un empleador privado en sus relaciones laborales? o, por el contrario, ¿se encuentran obligadas a observar exigencias públicas?

En el sector público, las normas que regulan la relación laboral están determinadas por Ley, pudiendo ser el Estatuto Administrativo (2005) o cuerpos estatutarios especiales, por ejemplo, el Código del Trabajo (2003). En este último supuesto, por aplicación de la Constitución Política $(2005$, art. 19,21$)$ que exige una igualdad legislativa cuando el Estado desarrolla actividades empresariales, se encuentran las empresas del Estado, por tanto, a estos organismos no les son aplicables las normas que rigen a los funcionarios que laboran en los otros servicios que conforman la Administración Pública.

Si se toma en cuenta esta expresión de igualdad y se retoman las preguntas planteadas, se debería concluir que las empresas del Estado gozan de la misma libertad que un empleador privado en sus relaciones laborales, quedando exentas de la aplicación de principios públicos exigidos a otros entes estatales. Sin embargo, esta respuesta presenta un problema y envuelve un eventual riesgo.

El problema, es que no considera el carácter estatal de la empresa. El peligro que encierra es desproteger el interés público que justificó la creación del organismo empresarial, ya que podría significar, en la práctica, dar preeminencia a su carácter comercial y a los intereses exclusivamente individuales de sus trabajadores, por sobre su deber de servicialidad y el bien de la comunidad.

Estos organismos, encuentran su causa final en la protección de intereses o necesidades públicas que les han dado origen (Valdés Prieto, 2006, p. 119). Incluso la 
finalidad comercial de las empresas del Estado es relativa frente al fin de creación de estos organismos, cual es la satisfacción de la necesidad general para la cual ha nacido a la vida jurídico administrativa, Este resultado se explica, primero, porque su vinculación con el Estado es más estrecha que aquella que se produce entre privados regulados por el mismo código laboral (Bermúdez Soto, 2014, p. 435). Segundo, ya que en la actividad a reglamentarse predomina un interés general por sobre el interés del funcionario (Silva Cimma y Verdugo Lay, 1995, p. 195). Múltiples son los dictámenes emanados de la Contraloría General de la República que vinculan a las empresas del Estado con el interés público, por ejemplo, a propósito del uso de recursos económicos provenientes de aportes fiscales, señaló que la Empresa de Ferrocarriles del Estado debe, en la gestión de dichos recursos, "... resguardar en todo momento el interés público..." (Dictamen № 34313, 1993) ; también señala, a propósito de las funciones de los Astilleros y Maestranzas de la Armada, que en éstas "...va implícito un interés público relacionado con la defensa de la nación..."(Dictamen $\left.N^{\circ} 78502,2013\right)$; y el Dictamen № 20108 que las vincula a la existencia de una necesidad pública, al indicar que "...cuando la ley decide crear una empresa pública, es porque estima que existe una necesidad pública comprometida y por ello, precisamente, tal clase de entidades integran la administración estatal, conforme ley 18575 art/1" (1994).

En razón de lo anterior, el presente trabajo busca exponer el ámbito público de las relaciones laborales que se producen en las empresas del Estado, como forma de resguardar el interés colectivo que caracteriza a estos organismos, sin que ello signifique desconocer el carácter de empleador de la empresa, sujeta a normas de derecho común, y las legítimas pretensiones laborales de sus funcionarios.

Para ello, el artículo se fundamenta en dos premisas: i) las empresas creadas por ley se encuentran condicionadas a principios públicos por ser estatales, y ii) sus trabajadores detentan la calidad de funcionarios públicos. A partir de estas premisas, y teniendo en cuenta la gestión del interés público al cual está destinada la empresa, se deducen las consecuencias jurídicas y su importancia para el organismo empresarial, en su calidad de empleador, y para los trabajadores, en cuanto titulares de derechos colectivos.

La importancia del artículo, radica en un aspecto teórico y práctico. El primero, obedece a la orfandad en que se encuentran las empresas del Estado como objetos de reflexión, lo cual motiva generar espacios de discusión que, a su vez, permitan conocer el régimen jurídico de una institución siempre controvertida, las acciones empresariales de carácter público siempre se encuentran unidas a un cierto grado de sensibilidad social y de cuestionamiento sobre la efectiva necesidad de dicha pretensión (Santa María Pastor, 2004, p. 313). Por lo mismo, se efectúa un examen no solo de la doctrina, leyes y jurisprudencia, sino que también se incluyen pronunciamientos administrativos dictados a propósito de dichos organismos. 
Empresas del Estado y su vinculación al Derecho Público Chileno en materia laboral.

La segunda importancia se justifica por los diversos problemas que se pueden presentar, como consecuencia de los distintos intereses que confluyen en las relaciones laborales de tales entes: el de la comunidad, el de los trabajadores y el de la empresa, esta última como organismo mercantil y administrativo a la vez.

Se previene, que el artículo aborda únicamente las actuaciones laborales realizadas por las empresas públicas creadas por ley. Luego, se excluyen de este análisis otras vías a través de las cuales el poder público concreta similares acciones, por ejemplo, las sociedades estatales.

\section{Las empresas del Estado como empleadoras y principios públicos}

Lo primero que se debe dejar establecido es que las empresas estatales, como empleadoras, se encuentran en la obligación de respetar los principios públicos que regulan el actuar de todos los organismos pertenecientes a la administración estatal.

Esta afirmación se fundamenta, primero, en la reserva de Derecho Público que consagra la Constitución Política. Cuando la Carta fundamental se refiere a los órganos del Estado, no está limitando su alcance solo a aquellos que desarrollan actividades en el ámbito público o que ejerzan sus funciones por medio de prerrogativas públicas, sino que se está refiriendo a todas las entidades que sean expresión del Estado, que tengan un control estatal, ya que lo relevante no es la naturaleza pública o privada de la actividad que realicen, sino que el carácter público y estatal del sujeto que las concreta, es lo que se ha denominado la aplicación directa de la Constitución, que se refiere al efecto vinculante, mediato o inmediato de las normas constitucionales sobre toda persona, institución o grupo, por tratarse de una norma jurídica superior que manda, prohíbe, permite o configura los principios para que ello acontezca. La fuente de la aplicación directa se encuentra en el Capítulo I, al indicar su artículo 6, inciso segundo, que "... los preceptos de esta Constitución obligan tanto a titulares o integrantes de dichos órganos como a toda persona, institución o grupo", (Constitución Política de la República de Chile, 2005, art. 6, inc. 2, citada en García Pino, y Contreras Vásquez, 2014, p. 86). A lo cual se debe sumar el alcance que la doctrina y la jurisprudencia le han otorgado a dicho capítulo, en el sentido que permite entender, de manera coherente y sistemática, el sentido del resto de las disposiciones constitucionales (Silva Bascuñán, 1997, pp. 18 y 19), y que la Constitución debe ser interpretada en conformidad con lo que establecen las Bases de la Institucionalidad, especialmente cuando se aplican técnicas de interpretación sistemática y teleológicas, como por ejemplo en la sentencia Rol N 19-1983 del Tribunal Constitucional de Chile (1983, cons. 9).

Por tal motivo, es que toda la Administración Pública, sin excepción alguna e independiente del objeto legal, se encuentra en la obligación de respetar principios constitucionales, como el de legalidad, transparencia y control, y uno de los orga- 
nismos que integra dicha Administración, por expreso y claro mandato legislativo, son las empresas públicas creadas por ley, según la Ley № 18.575 (1986, art. 1). Consecuentemente, éstas se encuentran sujetas a la observancia de principios públicos contemplados en la Carta Fundamental, y en el artículo 3 de la ley de Bases de la Administración del Estado.

No obstante lo expuesto, podría surgir una interpretación que excluya a las empresas públicas de la observancia de dichos principios, fundamentada en que la Ley $N^{\circ} 18.575$ (1986, art. 21) exceptúa a tales organismos de las normas contenidas en su Título II, y los somete, en lo que respecta a su organización y funcionamiento, a sus respectivas leyes de quórum calificado, las cuales, a su vez, contemplan un régimen jurídico de Derecho Privado y no permiten la aplicación de otra normativa, salvo determinadas circunstancias. Por ejemplo, el Decreto que crea la Corporación Nacional del Cobre, señala que "Las normas legales dictadas o que se dicten para las Empresas del Sector Público, (...) solo serán aplicables [a dicha corporación] (...) en caso de que se haga referencia expresa a ella en la norma legal respectiva..." (Decreto № 1.350, 1976, art. 25).

Sin embargo, la Contraloría General de la República se ha encargado de poner freno a esta eventual conclusión, señalando, a propósito de las leyes orgánicas de cada empresa, que la Ley 18.575

... de rango orgánico constitucional y dictado acorde art/38 de la ley suprema (...) tiene por objeto consagrar principios básicos de organización y funcionamiento de los entes públicos, tales como los de legalidad, competencia, eficiencia, unidad, jerarquía, disciplina, control, probidad y responsabilidad, de cuya aplicación ninguna entidad de la administración estatal podría estimarse marginada (Dictamen № 20108, 1994)

El mismo criterio es utilizado en dictámenes $N^{\circ}$ s 21763 (2004) y 7846 (2017), y en sentencia del CIMM Tecnologías y Servicios S.A. con Fisco de Chile y Contraloría General de la República (2010), a través de la cual se señaló que

...el artículo $1^{\circ}$ de la Ley Orgánica Constitucional de Bases Generales de la Administración del Estado, en cumplimiento del mandato previsto en el inciso primero del artículo 38 de la Constitución, determina la organización de la Administración del Estado, precisando quienes son los órganos y entidades que la constituyen, estableciendo expresamente que las empresas públicas creadas por ley, forman parte de la Administración del Estado. (cons. 22)

En razón de ello, el órgano contralor ha concluido que las normas contenidas en las leyes de creación de las empresas del Estado y que las excluyen, expresamente, de las disposiciones que rigen o rijan a los organismos empresariales públicos, no significa excluirlas de la normativa de Derecho Público que, atendida su naturaleza jurídica de empresa integrante de la Administración estatal, les pueda resultar apli- 
Empresas del Estado y su vinculación al Derecho Público Chileno en materia laboral.

cable (Dictamen $\left.N^{\circ} 28925,2006\right)$, como serían los principios públicos consagrados a nivel constitucional y en la Ley $N^{\circ} 18.575$ (1986).

Cabe agregar que, cuando las leyes orgánicas de estas entidades excluyen la posibilidad de aplicar otra normativa, dicha exclusión solo debe ser entendida en el sentido de no utilizar el Derecho Público en las relaciones jurídicas de la empresa actuando en el mercado, pero no en lo que respecta al resguardo de los intereses públicos puestos en el funcionamiento de dicho organismo, ya que en este caso no se está hablando de la empresa solo en el sentido económico de la misma, sino que se está en presencia de un órgano público que se relaciona con quien hace las veces de su propietario, quien es la comunidad representada en el Estado. Desde esta perspectiva, el Derecho Público se presenta como un elemento que otorga garantía a toda la colectividad, porque evita o dificulta el ejercicio abusivo del Derecho Privado y se constituye, al mismo tiempo, en un elemento al cual recurrir para interpretar la regulación específica de tales entes administrativos, (Cordero Vega, 2015, pp. 184 y 189). Además, como lo ha señalado la jurisprudencia, el hecho de que las empresas del Estado se rijan por normas que son propias del sector privado, "...no es sino una ficción legal destinada a facilitar su actividad comercial, que no puede tener la virtud de alterar la real naturaleza de la entidad, más aun, cuando ella debe confrontarse en relación con normas de rango constitucional" (Banco del Estado de Chile con Fisco, 2009, cons. 9).

Lo expuesto permite reiterar el enunciado inicial, cual es que las empresas estatales se encuentran condicionadas a principios públicos no por el tipo de actividad que realizan, sino que por formar parte de la Administración Pública, es decir, por la existencia de un poder público capaz de dirigir las decisiones de la empresa (Troncoso Reigada, 1997, p. 201).

Demostrado lo anterior, corresponde precisar los principios a los cuales se encuentran sujetos estos organismos en su condición de empleadores, y que permiten dar protección al interés público inserto en el funcionamiento de los mismos, se reitera que cuando el Estado interviene en la sociedad a través de estructuras empresariales es para satisfacer un interés público (Álvarez de la Rosa, 1987, p. 231 ; Rivero Ysern, 1978, p. 15), incluso dicho interés debe ser de carácter relevante (Ariño Ortiz y López de Castro García-Morato, 2004, p. 474). Para ello, se deberá efectuar un análisis desde el punto de vista de la (1.1.) selección del personal y (1.2.) de las fuentes jurídicas que regulan la actuación de la empresa estatal.

\subsection{Principios públicos en la selección del personal}

No existe duda, que el empresario privado es titular de una amplia autonomía en lo que respecta a la selección del personal que prestará servicios en su empresa. Su libertad se restringe solo por aspectos formales y de respeto a los derechos de los trabajadores, por ejemplo, respetar la irrenunciabilidad de los derechos laborales 
consagrada en el Código del Trabajo (2003, art. 5). Esta situación es complemente distinta a lo que ocurre con trabajadores del sector privado. En estos casos, los beneficios otorgados por el empleador, de forma permanente e invariable, constituyen una estipulación tácita incorporada en el contrato, por lo que no puede ser modificada o suprimida por la voluntad de una de las partes. Es decir, se entiende que éstas, tácitamente, han modificado o complementado el pacto laboral, razón por la cual, su otorgamiento se transforma en un derecho exigible para el trabajador. Lo expuesto se fundamenta en el Código Civil (2000, art. 1564), que permite interpretar las cláusulas contractuales por la aplicación práctica que hayan hecho de ellas ambas partes, o una de ellas con aprobación de la otra (Thayer Arteaga y Novoa Fuenzalida, 2003, p. 35), pero siempre subyace, como fundamento principal, su libertad en lo que respecta a la elección del personal.

Sin embargo, la situación es distinta cuando se trata de seleccionar trabajadores que prestarán servicios en alguna empresa estatal. Como se señaló previamente, éstas forman parte de la Administración Pública, razón por la cual, en su condición de empleadoras se encuentran vinculadas a principios constitucionales, como son el de igualdad en el acceso a todos los empleos públicosy el de objetividad.

Con respecto al primero, el imperativo en que se encuentran las empresas del Estado se traduce, de conformidad a la Ley $\mathrm{N}^{\circ} 18.575$ (1986, art. 15), en respetar los requisitos establecidos en el Código del Trabajo (2003), a saber, las exigencias sobre mayoría de edad y de nacionalidad; y los contemplados en las leyes respectivas de cada una de las empresas estatales, por ejemplo, deberán acatar todo el régimen relativo a las incompatibilidades e inhabilidades, como ejemplo de incompatibilidad puede consultarse el Decreto Ley № 2.079 (1978, art. 15), que fija el texto de la ley Orgánica del Banco del Estado, y que se remite a las incompatibilidades que rigen a los directores de bancos comerciales. En lo pertinente a las inhabilidades, se pueden mencionar aquellas de carácter moral, por ejemplo, no haber sido condenado ni encontrarse acusado por delito que merezca pena aflictiva, según Decreto Ley $\mathrm{N}^{\circ} 1.350$ (1976, art. 8,a), que crea la Corporación Nacional del Cobre, y la Ley Nº.618 (1950, art. 5), Orgánica de la Empresa Nacional del Petróleo. A estas exigencias, se deben sumar las normas constitucionales que correspondan y lo establecido en el Título III de la Ley $N^{\circ} 18.575$ (1986), referente a la prohibición impuesta a determinadas personas para ingresar a la función pública.

El segundo principio, es el de la objetividad en la selección del personal. Éste exige la concurrencia de requisitos de carácter técnico y profesional para ingresar a la función pública, luego, las empresas estatales son competentes para exigir requerimientos técnicos a fin de proveer un determinado cargo o función. Esta potestad, responde a la exigencia constitucional de mérito y competencia establecida en la Constitución Política (2005, art. 38) y la Ley № 18.575 (1986, art. 16), última disposi- 
Empresas del Estado y su vinculación al Derecho Público Chileno en materia laboral.

ción que contempla, precisamente, la posibilidad de establecer requisitos en razón del cargo que se provea.

Para lograr lo anterior, el organismo empresarial deberá constituir medios idóneos de diagnóstico y de decisión que permitan la calificación o ponderación de las características, condiciones, aptitudes u otros antecedentes de los participantes, en este punto resalta la Ley № 19.132 (1992, art. 31), que crea la Empresa Televisión Nacional de Chile, toda vez que exige, para efectos de la selección del personal, que ésta se realice mediante procedimientos técnicos, imparciales e idóneos, que aseguren una apreciación objetiva de las aptitudes y méritos de los postulantes. La finalidad es que la persona a seleccionarse sea la más idónea para desempeñar el cargo de que se trata - una forma de dar cabida a este objetivo puede ser la contratación de servicios especializados en la selección de personal, como se señaló en el Dictamen No 89805 (2014). Éste ratificó la legalidad del acuerdo del Directorio de la Corporación Nacional del Cobre, que decidió contratar a una consultora internacional para la elección del Presidente Ejecutivo de la empresa-, y, de dicho modo, responder a las necesidades de la empresa, según lo dispuesto en la Ley $\mathrm{N}^{\circ}$ 18.575 (1986, art. 53).

La importancia de ambos principios se puede observar desde una doble perspectiva. La primera se refiere al control, como medio de protección al interés público involucrado en la gestión de la empresa, ya que si bien ambas exigencias, la de igualdad en el acceso a la función pública y la de objetividad, se pueden arbitrar desde el derecho laboral, el Código del Trabajo (2003, art. 2) consagra el principio de la no discriminación en la selección del personal. Éste ha sido definido en el Convenio sobre la discriminación (empleo y ocupación) (1960), como "cualquier otra distinción, exclusión o preferencia que tenga por efecto anular o alterar la igualdad de oportunidades o de trato en el empleo u ocupación..." (art. 1, b) y se ha estimado que opera en el momento de la contratación del personal, durante la vigencia del vínculo contractual y en las situaciones de despido (Thayer Arteaga y Novoa Fuenzalida, 2003, p. 20). Su consagración como principios de Derecho Público las transforma en imperativos indisponibles para la empresa en su calidad de empleadora, a pesar de encontrarse regulada por normas de derecho laboral común, lo cual disminuye las posibilidades de adoptar decisiones arbitrarias por parte de la Administración (Silva Bascuñán, 2010, p. 358 y Evans de la Cuadra (1999, p. 270). Además, a través de la exigencia de igualdad en el acceso a todas las funciones públicas, se concreta la igualdad de oportunidades y de concreción del bien común que exige el artículo primero de la Constitución Política, Marín Vallejo (2000, p. 219).

La segunda importancia se encuentra vinculada al aspecto técnico de las empresas del Estado. En efecto, si bien tales organismos son creados por ley y forman parte de la Administración Pública, lo cierto es que se está en presencia de entes de carácter empresarial que se desenvuelven en el mercado, razón por la cual, requieren 
conocimientos y prácticas técnicas para el cumplimiento eficiente y eficaz de su objeto. Las empresas estatales, en tanto integrantes de la Administración del Estado, deben gestionar el patrimonio público "...de un modo congruente con los principios rectores de la función pública, entre los cuales se encuentra la eficacia y eficiencia y, por ende, deben velar por la consecución de sus objetivos con el costo más conveniente para ello" (Dictamen N 83983, 2014); la misma idea está presente en el Dictamen No 16511 (2015). Consecuentemente, si el nombramiento de los funcionarios se va a efectuar teniendo en cuenta requisitos distintos a rasgos como la idoneidad, vocación y capacitación profesional, por ejemplo, designaciones motivadas en razones de fidelidad política (Martín-Retortillo, 1988, p. 220), se podría obstaculizar el cumplimiento de tales exigencias y perjudicar el rendimiento comercial de dichos organismos, además, se podrían generar otras consecuencias negativas, tales como aumentar el tamaño que, razonablemente, debe tener el Estado-Administrador, entrabar soluciones a problemas importantes e impedir la proporción armónica que debe existir entre los cometidos, propiamente públicos, con las funciones que el principio de subsidiariedad le reconoce a los grupos intermedios, (Caldera Delgado, 1996, p. 223). En definitiva, atentar en contra del interés público inserto en el actuar económico de la empresa.

Sobre la base de lo expuesto, es posible concluir que estos organismos se encuentran sujetos a principios públicos en lo que respecta a la selección de su personal, cuales son el de igualdad y el de objetividad. Su importancia es que facilitan una actuación eficaz e indiferente- el principio de la eficacia indiferente, es un mecanismo que permite un correcto e imparcial ejercicio de las competencias por parte de las autoridades administrativas. Éste exige a la institución y a los propios funcionarios ser eficaces, tanto si se perjudica como si se favorece la política de los gobernantes de turno que se encuentren en el poder, (Garrido Falla, Palomar Olmeda y Losada González. 2010, p. 72)- de la empresa estatal, al facilitar la objetividad en los nombramientos, un correcto uso de los recursos públicos y evitar o restringir la arbitrariedad de la Administración, todo lo cual se traduce en una preeminencia del interés general por sobre el interés particular de la empresa y de la persona interesada en ingresar a la función pública.

\subsection{Principios públicos en la celebración del contrato de trabajo}

El segundo momento en el cual, como empleadoras, las empresas del Estado deben sujetarse a principios públicos, es en la celebración del contrato del trabajo, principalmente en lo que respecta a las cláusulas que contendrá dicha convención.

Se sabe que el Código del Trabajo (2003) permite, al empleador y trabajador, celebrar los pactos que estimen pertinentes para proteger sus intereses, esta afirmación se desprende, principalmente, del № 7 del artículo 10 del Código del Trabajo, al señalar que el contrato de trabajo deberá contener los demás pactos que acordaren 
Empresas del Estado y su vinculación al Derecho Público Chileno en materia laboral.

las partes, ya sea para regular aspectos no abordados por la ley o para mejorar las condiciones del trabajador (Thayer Arteaga y Novoa Fuenzalida, 2003, pp. 225 y 226), es decir, un contrato de trabajo puede contener todas aquellas cláusulas que acuerden las partes, en virtud a su autonomía, y que consideren necesarias para su protección, pudiendo, incluso, pactarse de manera tácita.

Sin embargo, nuevamente la situación no es la misma tratándose de las empresas del Estado, toda vez que respecto de ellas lo que rige es el principio de juridicidad y no el de autonomía, a pesar de que se encuentran reguladas por la misma legislación laboral que el sector privado, de conformidad con lo dispuesto en la Constitución Política (2005, art. 19, 21). Lo anterior se explica, porque la exigencia de igualdad que impone el constituyente no significa transformar al ente estatal en una empresa particular, completamente independiente en su gestión, sino que "...garantizar (...) que en aquellos casos en que el Estado y sus organismos desarrollen actividades empresariales, no estarán sujetos a normas preferenciales, sino que a la misma legislación común aplicable a particulares" (Televisión Nacional de Chile con Contraloría General de la República, 1994, cons. 7).

Por tanto, la exigencia de regulación de derecho común, ya sea laboral, civil o comercial, no altera la calidad de órgano público de la empresa (Aróstica Maldonado' 2001, p. 110), ésta sigue siendo expresión del Estado, luego, y al igual que cualquier otro ente público, debe ser el principio de juridicidad el que guíe, tanto en lo formal como en el fondo, toda la actuación del organismo mercantil. Esta afirmación ha sido expresada por la propia Corte Suprema, al indicar, a propósito de la empresa de Ferrocarriles del Estado, que "... se está frente a una empresa pública donde prevalece el principio de legalidad de los artículos 6 y 7 de la Carta Fundamental (...) y respecto de los cuales debe ajustar todas sus actuaciones" (Empresa de los Ferrocarriles del Estado con Corvalán Morales y Otro, 2012, cons. 9), lo mismo ha señalado la Contraloría a través de su Dictamen No 9008 de 1992, al establecer que las autoridades de una empresa estatal están sometidas a los principios de legalidad y competencia, contenidos en la Constitución Política (2005, arts. 6 y 7 )

Este predominio del principio de juridicidad en el ámbito laboral de las empresas estatales, significa que, no obstante estar facultadas para contratar personal regido por el Código del Trabajo, esta autorización

...debe entenderse (...) en armonía con las limitaciones y modalidades a que dicho órgano se encuentra afecto dado su carácter de ente público que debe sujetarse estrictamente a los mandatos constitucionales y legales que rigen su actuar.

(...) las normas contenidas en el Código del Trabajo (...) no pueden aplicarse con la misma amplitud que en el caso de un administrador privado, cuando regula las relaciones laborales en una entidad del Estado, porque en las reparticiones públicas (...)las personas naturales, que actúan como adminis- 
tradores, deben sujetarse a la ley y al fin del servicio a que pertenecen. (Dictamen $\left.\mathrm{N}^{\circ} 55344,2006\right)$

Consecuentemente, y en lo relativo a la celebración de cláusulas laborales que formarán parte del respectivo contrato de trabajo, es el principio de juridicidad y no el de autonomía de las partes, como ocurre con un empleador privado, el que debe guiar la actuación de la empresa estatal. Siendo dos son las fuentes jurídicas, en concreto, que actúan en dicha configuración: la ley y el propio contrato.

La ley en razón del mismo principio. Luego, las cláusulas de la convención laboral se deberán restringir a lo contemplado en el Código del Trabajo, al señalar que

cuando por mandato legal se afecta a funcionarios de la administración a la legislación laboral común, ésta adquiere para ellos y la institución el carácter de estatuto jurídico de derecho público, en razón de la naturaleza del organismo y especialidad del vínculo existente, aplicándosela dentro del marco de principios y normas peculiares, en materia de investidura, competencia y responsabilidad, etc, reconocidos por la Constitución y que no tienen aplicación en relaciones laborales del sector privado. (Dictamen No 19383, 2001).

Por ejemplo, los artículos 159 y 160, si el organismo público quisiera poner fin a la relación laboral, y a lo dispuesto en el resto del ordenamiento jurídico que rige el actuar de las empresas estatales, principalmente lo señalado en la ley de creación de cada una de ellas.

En la segunda fuente, el contrato, se deberán consignar las condiciones laborales y los eventuales beneficios pactados a favor de los trabajadores, según lo señalado en los artículos 10 y 11 del código laboral. Al respecto, la Contraloría General de la República ha indicado que, cuando las normas de dicho cuerpo normativo rigen a determinados servidores del Estado, la autoridad administrativa también se encuentra obligada por lo establecido en los contratos de trabajo legítimamente pactados (Dictamen No55344, 2006).

No obstante lo señalado en relación al principio de juridicidad, es decir, que éste actúa como límite en el actuar de las empresas públicas al momento de definir el contenido de la relación laboral, es válido preguntarse qué ocurre con la autonomía financiera de estos organismos -junto con reconocerse, a nivel legal, que estos organismos gozan de patrimonio propio, la Ley $N^{\circ} 18.196$ (1982, art. 11) los sustrajo del sistema de administración financiera general del Estado, consecuentemente, no se rigen por la ley de presupuesto que se dicta anualmente para el sector público-, específicamente, si pueden celebrar pactos laborales que incidan directamente en su patrimonio, por ejemplo, aquellos relacionados con salarios, indemnizaciones o cualquier otro beneficio económico. La pregunta se fundamenta en el propio Código Laboral, que, como se señaló, representa la legalidad de la empresa en sus actuacio- 
Empresas del Estado y su vinculación al Derecho Público Chileno en materia laboral.

nes laborales, toda vez que dicho cuerpo normativo, al autorizar la celebración de este tipo de cláusulas, solo establece el marco mínimo y general en el cual deben desarrollarse (Dictamen $N^{\circ} 24056,2008$ ), pero no señala la forma, procedencia y monto del pago, por tanto, y especificando la pregunta, ¿es lícito para la empresa estatal concertar libremente estos aspectos con sus trabajadores, al igual que un empleador privado?

Una respuesta positiva a esta interrogante, envuelve el riesgo de pactar prestaciones económicas cuyos montos, formas y causas privilegien el interés legítimo, pero individual, de los funcionarios, ya sean trabajadores o directores, por sobre el interés público que justificó la creación del organismo mercantil. A su vez, una respuesta negativa podría anular el carácter comercial de la empresa y reducirla a las lógicas de funcionamiento de cualquier servicio público, ignorando su autonomía financiera.

Una posibilidad de solución al primer riesgo planteado, cual era dar relevancia a un interés particular por sobre el colectivo, es, nuevamente, el principio de legalidad, al establecer restricciones al actuar de las empresas públicas como empleadoras, justificadas, precisamente, en el imperativo de dar preeminencia al interés general por sobre cualquier otro tipo de pretensión, y en el carácter público de los recursos (Cuétara Martínez, 1983, p. 494) que administran tales organismos. Estas limitaciones se pueden expresar de dos formas.

La primera, se refiere a la vinculación positiva (Cordero Vega, 2015, p. 76) de la empresa a las normas que autorizan este tipo de prestaciones. Esto significa que solo pueden celebrarse aquellos pactos expresamente establecidos o autorizados por la ley (Dictamen $\left.N^{\circ} 19383,2001\right)$ y en la forma y oportunidad que la propia legislación señale. Es decir, las empresas públicas sí pueden celebrar pactos de contenido económico con sus trabajadores, pero solo aquellos contemplados expresamente en el Código del Trabajo y en leyes complementarias, por consiguiente, no es posible conceder ayudas que no se encuentren permitidas a nivel legal. Como ejemplos de beneficios que se pueden convenir entre dichos organismos públicos y sus trabajadores, están los de movilización y colación, siempre que así se disponga en sus respectivos contratos (Dictamen No 11574, 2006). Como ejemplo de ayuda que no se puede otorgar por no estar consagrada a nivel legal, se encuentra la celebración de un contrato de seguro de responsabilidad civil por la Empresa Nacional del Petróleo a favor de sus directores, y respecto del cual la Contraloría señaló que

...los estipendios que la Administración del Estado pacte con su personal sujeto al Código del Trabajo deben constituir (...) una contraprestación de los servicios realizados por causa del contrato de trabajo y no pueden establecerse en consideración al comportamiento funcionario o provenir de la mera liberalidad del empleador... (Dictamen № 50239, 2013) 
Además, que para contratar dicho seguro se "...requiere una autorización expresa concedida por ley, por cuanto el pago de la prima (...) implica incurrir en un gasto extraordinario que no corresponde a los objetivos que le compete desarrollar acorde con su marco jurídico..." (Dictamen No 50239, 2013). Otro caso es la imposibilidad en que se encuentran las empresas del Estado para conceder mutuos o préstamos de dinero a favor de sus empleados y sindicatos, por no estar permitido a nivel legal (Dictamen No 14944,1991 y Nº 17578, 2007).

Esta conclusión ha sido formulada expresamente por la Contraloría General de la República, a propósito de las indemnizaciones que se otorgan a los trabajadores de dichas entidades, señalando que éstas no se pueden pactar

por conceptos diversos a los previstos en la legislación, ni fijar modalidades de pago diferentes de las previstas.[sic] las reglas sobre pago de indemnizaciones por cese de funciones son materia de seguridad social, tema sobre el cual no existen normas legales que permitan a las empresas del Estado fijar condiciones particulares a sus trabajadores, (...) rigiendo el mandato imperativo para las autoridades de aplicar solo los beneficios legales, sin poder establecer franquicias mayores o distintas por vía contractual. (Dictamen $\mathrm{N}^{\circ}$ 19383, 2001)

Un ejemplo concreto de que las empresas públicas deben sujetarse al principio de juridicidad en lo que respecta a la celebración de pactos de contenido económico, lo constituye las indemnizaciones que se han debido otorgar a propósito de los planes de restructuración y modernización de estos organismos, toda vez que han sido sus propias leyes orgánicas las que han especificado, de manera expresa, un régimen de compensaciones económicas que comprende las causas, requisitos y montos de dichos resarcimientos ${ }^{1}$, no dejando entregada la definición de estos aspectos a la autonomía de la empresa.

Junto a lo anterior, se debe respetar una legalidad formal, por ejemplo, la exigencia de escrituración de dichos pactos, según el Código del Trabajo (2003, art. 9) esta exigencia significa que se deberá establecer de manera específica, y en los respectivos contratos de trabajo, la forma, periodo y monto de pago de la prestación que corresponda, toda vez que la voluntad de un organismo público "...solo puede exteriorizarse y producir efectos jurídicos siempre que ella se exprese en términos formales y explícitos, sin que sea procedente aceptar que aquél tenga una voluntad distinta a la manifestada de ese modo..."(Dictamen No 55344, 2006). Lo mismo en pronunciamiento № 2096 (1988), - específicamente respecto de Televisión Nacional de Chile-, excluyendo con ello la posibilidad de cláusulas tácitas, esta situación es complemente distinta a lo que ocurre con trabajadores del sector privado. En estos casos los beneficios otorgados por el empleador, de forma permanente e invariable, constituyen una

\footnotetext{
${ }^{1}$ Puede consultarse los artículos transitorios 28 de la ley Orgánica de la Empresa de Correos de Chile, 4 de la ley que Moderniza el Sector Portuario Estatal y 3 de Ferrocarriles del Estado (1993).
} 
Empresas del Estado y su vinculación al Derecho Público Chileno en materia laboral.

estipulación tácita incorporada en el contrato, por lo que no puede ser modificada o suprimida por la voluntad de una de las partes. Es decir, se entiende que éstas, tácitamente, han modificado o complementado el pacto laboral, razón por la cual, su otorgamiento se transforma en un derecho exigible para el trabajador. Lo expuesto se fundamenta en el Código Civil (2000, art. 1564), que permite interpretar las cláusulas contractuales por la aplicación práctica que hayan hecho de ellas ambas partes o una de ellas con aprobación de la otra (Thayer Arteaga y Novoa Fuenzalida, 2003, pp. 227 y 228). Lo contrario hará presumir la inexistencia jurídica de la estipulación en particular, aun cuando en los hechos se estuviere concretando. Un ejemplo de la obligatoriedad a que están sujetas las empresas del Estado de tener que expresar su voluntad de manera explícita en materia de remuneraciones, se encuentra en el Dictamen No 61085 (2015). A través de éste, la Contraloría señaló que el Directorio de la Empresa Portuaria de Puerto Montt no dio cumplimiento a lo previsto en el artículo 37 de la ley que regula el sector portuario estatal, ya que no determinó, específicamente, el monto del incremento remuneracional que se acordó a favor del gerente general de dicha empresa.

Una segunda forma de restricción a la discrecionalidad de las empresas del Estado en la celebración de este tipo de pactos, es el deber de los órganos de la Administración Pública de adoptar decisiones imparciales, de conformidad con la Ley $\mathrm{N}^{\circ}$ 18.575 (1986, art. 53). Esto significa, en términos simples, que las empresas públicas se encuentran condicionados a actuar como parte interesada, y su interés debe ser materializar el objeto impuesto por el legislador, en este caso, la exigencia legal de imparcialidad no significa actuar como un tercero neutral entre el interés de los trabajadores, completamente válido, y el de la comunidad, que debe ser la beneficiada de la respectiva explotación comercial, sino que en la obligación de aplicar la ley de manera objetiva, ajena a cualquier otro tipo de interés o fin, García Costa (2011, pp. 30 y 32). Por tanto, las decisiones del ente estatal, aun cuando se deban adoptar en un margen de autonomía, no pueden basarse en ningún tipo de subjetivismo personal, laboral o partidario, sino que deben fundarse, exclusivamente, en la voluntad de la ley (García Costa, 2011, pp. 28-31). Precisamente porque la imparcialidad se refiere a que el órgano administrativo debe cumplir el objeto impuesto por ley, ajeno a cualquier otra subjetividad, es que se consagran los conflictos de interés. Como se sabe, éstos buscan evitar cualquier circunstancia que pueda restarle imparcialidad a un agente público en el ejercicio de la función pública (Barra Gallardo, 2004, p. 83).

Aplicado al caso concreto, cual es la celebración de cláusulas laborales y de contenido patrimonial, se debe concluir que, por amplia que sea la autonomía financiera de la empresa, en lo que respecta a la posibilidad de convenir el monto de las remuneraciones, indemnizaciones u otros beneficios económicos - esta libertad se desprende del Decreto Ley № 2.758 (1979, art. 14 transitorio), que Establece Normas sobre Negociación Colectiva. Dicha disposición autorizó al Presidente de la República para derogar las normas limitativas de remuneraciones que se aplicaban al personal 
de las empresas del Estado, razón por la cual, estos organismos deben sujetarse a las normas de reajustes y fijación de sueldos y salarios del sector privado. En relación con ello, el Código del Trabajo (2013, art. 44) solo establece una base mínima desde la cual poder convenir una cantidad, por lo que en el concepto de remuneración se puede incluir toda retribución en dinero que el trabajador perciba producto de su contrato de trabajo, (Lizama Portal, 2005, pp. 134-136). Lo expuesto es distinto a lo que ocurre con otros organismos públicos, en que el monto de los salarios se encuentra fijado por ley, consecuentemente, no existe ninguna posibilidad de alterar dicha cantidad-, el organismo público se encuentra en el imperativo de observar el objeto legal para el cual fue concebida la empresa estatal, es decir, ésta debe actuar interesada en que el contenido de dichas estipulaciones efectivamente vaya a incidir, de manera directa, en una concreción eficiente y eficaz del giro comercial, con lo cual se está dando preeminencia al interés general, representado en el objeto, por sobre intereses individuales.

Esta exigencia de imparcialidad no significa un actuar desproporcionado e irracional de la empresa pública, que ignore y desproteja el interés de los trabajadores. Por el contrario, al organismo empresarial le debe interesar generar condiciones laborales que faciliten y motiven un correcto actuar de sus funcionarios, porque la función pública constituye un medio relevante para dar cumplimiento a su mandato legal, es decir, es necesaria para alcanzar la finalidad deseada (Bermúdez Soto, 2014, p. 555). Lo que se le está exigiendo al ente público es un actuar proporcionado (Cordero Vega, 2015, p. 93), que logre, por una parte, evitar excesos que se sobrepongan al interés de la ciudadanía, $y$, por otra, actuaciones arbitrarias que no respeten legítimas pretensiones laborales.

Este actuar proporcionado podría evitar el segundo riesgo planteado, cual era anular la autonomía financiera del organismo público en sus relaciones laborales, toda vez que permitiría pactar cláusulas de contenido económico que sean acordes a las reglas del mercado y del sector económico donde se desenvuelve la empresa, y que, junto con ello, logren conciliar el interés de la comunidad. Además, permitiría dar concreción al principio de la libertad de trabajo, en el sentido que el ente empresarial será libre para contratar y ofrecer condiciones laborales acordes a su realidad, y el trabajador, según una concepción ética-social de la remuneración (Thayer Arteaga y Novoa Fuenzalida, 2003, pp. 312-313), podrá elegir al empleador que más le beneficie (Zavala Ortiz y Morales Godoy, 2004, p. 21).

En este punto, un instrumento que puede servir como medida para equilibrar el interés de la comunidad y el de los funcionaros, son las instrucciones sobre disposición de recursos económicos impartidas por el Ministerio de Hacienda. Esta herramienta, ejercida en razón de la supervigilancia que debe efectuar el ejecutivo (Precht Pizarro, 1989, p. 466), este control, ejercido por el Ministerio de Hacienda, es consecuencia de lo dispuesto en la Ley $N^{\circ} 18.196$ (1982, art. 11) y en la Ley $N^{\circ} 18.382$ (1984, 
art. 11), sobre Normas Complementarias de Administración Financiera, Personal y de Incidencia Presupuestaria del Estado, que obliga a las empresas públicas, en general, a obtener la aprobación de sus presupuestos por parte de los Ministerios de Hacienda, de Economía y de aquél a través del cual se relacionen con el ejecutivo. El Dictamen № 7116 (2018) confirma la observancia de estas orientaciones respecto de las empresas estatales, fundamentado en la obligación del Ministerio de Hacienda de dirigir la política financiera del Estado, así como la recaudación de las rentas públicas y su administración, encontrándose facultado para dictar normas e instrucciones relativas a tales materias, permite a las empresas estatales pactar cláusulas de contenido económico con sus trabajadores, pero sujetándose a ciertos parámetros en lo que respecta al monto de las remuneraciones, indemnizaciones y beneficios a otorgarse. Por ejemplo, deben tener en cuenta los salarios alternativos de la región en que se encuentre ubicada la empresa. Se puede consultar la Circular № 15 del Ministerio de Hacienda (2018), el cual señala que por ser la empresa un ente singular, inserto en una realidad regional, "... no pueden pactarse remuneraciones ni beneficios que no den cuenta de la realidad de cada Empresa..." (n. 3). Otro ejemplo es el Ordinario № 2613 (2015), del Ministerio de Hacienda, sobre la base de la restricción fiscal del año 2016, que solicita modificar la reajustabilidad de remuneraciones de ejecutivos superiores en empresas del Estado y sociedades en que éste tenga participación.

Por tanto, volviendo a la pregunta planteada, cual era si la empresa estatal goza de autonomía para pactar la forma, procedencia y monto de beneficios económicos para sus trabajadores, se debe responder de manera positiva, con la salvedad que dicha autonomía no es idéntica a la de un empleador particular, sino que se ve condicionada por el principio de legalidad y por la exigencia de proceder como parte interesada en el cumplimiento de su giro mercantil. Condicionamientos que no persiguen anular la libertad financiera del organismo, sino que otorgar certeza en el uso del patrimonio público y evitar posibles excesos o actos de corrupción en la celebración de este tipo de cláusulas. En definitiva, dar preeminencia al interés público (Valdés Prieto, 2006, p. 119), al señalar que estos organismos se encuentran sometidos a una heteronomía, es decir, se rigen por lo que el legislador les ha impuesto como fines con el objeto de satisfacer una necesidad pública.

\section{Los trabajadores de las empresas estatales y los derechos colecti- vos}

Al igual que lo expuesto con las empresas creadas por ley, se debe partir de la premisa que los trabajadores de tales organismos, por el solo hecho de desempeñarse en un ente estatal, detentan la calidad de funcionarios públicos, no siendo razón, para excluirlos de tal carácter, que se encuentren regulados por las normas del Código del Trabajo, y que no les sean aplicables las disposiciones que rigen a los trabajadores que laboran en otros servicios de la Administración Pública. 
En efecto, como es sabido, todo el personal de la organización estatal se debe regir por las normas estatutarias que establezca la ley, según lo señalado en la Ley $\mathrm{N}^{\circ}$ 18.575 (1986, art. 15), por tanto, es el legislador quien dispone cual será el conjunto normativo que reglamentará una determinada función pública. Por ejemplo, puede ordenar que sea la Ley $N^{\circ} 18.834$ (1989) o el Código del Trabajo. Cualquiera sea el cuerpo de disposiciones que se establezca, recibe el nombre genérico de estatuto administrativo y deberá regular la relación órgano-funcionario que corresponda (Silva Cimma y Verdugo Lay, 1993, p. 115). Sin embargo, esta exigencia formal no tiene la capacidad de alterar lo sustantivo de la función pública, es decir, independiente de cual sea el grupo normativo definido por la ley, ésta sigue siendo una actividad realizada en nombre del Estado para poner en funcionamiento un determinado servicio público, por lo que la calidad de agente público es independiente de las normas que regulan al personal que se desempeña en cualquier organismo administrativo, ya que tal carácter, se reitera, se encuentra determinado por la naturaleza del servicio y no por las disposiciones que regulen su vinculación con el respectivo organismo.

La conclusión previa, específicamente respecto de trabajadores que laboran al interior de empresas estatales, ha sido reafirmada, desde antiguo, por la Contraloría General de la República, al señalar que éstos

...tienen la calidad de servidores públicos, cualesquiera que sean las normas que regulen sus vinculaciones con el respectivo organismo, sea que estos preceptos se contengan en el Código del Trabajo o en otros cuerpos legales, por cuanto en estos casos, tales textos legislativos constituyen, precisamente, el estatuto de sus derechos y obligaciones, mas no el elemento que determina su condición funcionaria, la que se encuentra preestablecida por la naturaleza del servicio respectivo. (Dictamen No 12350,1989)

Concepto también presente en Dictamen № 28226 (1994). A propósito de los directores de empresas estatales, el órgano contralor ha señalado que "...son funcionarios públicos por prestar servicios en un organismo de la Administración del Estado y, en tal calidad, están obligados a cumplir con la preceptiva constitucional y legal que regula el principio de probidad..." (Dictamen № 42380, 2012), lo mismo en pronunciamiento № 20108 (1994).

Es decir, el órgano de control considera la expresión estatuto administrativo como un concepto jurídico comprensivo del régimen integral a que están sometidos los funcionarios de las empresas estatales, por lo que tal expresión comprende todos los cuerpos estatutarios que rijan al personal de dicha administración pública (Pantoja Bauzá, 2000, pp. 79 y 80). Por tanto, los trabajadores de estos organismos ostentan la calidad de funcionarios públicos, Ello a pesar de que algunos textos orgánicos señalan que sus funcionarios se considerarán como trabajadores del sector privado, por ejemplo, los artículos 22 y 29 de las leyes orgánicas de Televisión Nacional (1992) y 
Empresas del Estado y su vinculación al Derecho Público Chileno en materia laboral.

de Ferrocarriles del Estado (1993), toda vez que esta expresión es solo "...una ficción legal destinada a facilitar la actividad comercial..." (Banco del Estado de Chile con Fisco, 2009, cons. 9) del organismo, pero no altera su naturaleza estatal. Además, a propósito de la empresa de ferrocarriles, la Corte Suprema, pronunciándose respecto de un Recurso de Casación que pretendía acreditar la calidad de empleado particular del gerente general de dicho organismo, a fin de eximirlo de responsabilidad penal, señaló que "...todos los elementos que previene el tipo penal se hallan en la descripción de los hechos (...), esto es, la condición especial del sujeto activo, empleado público" (Morgan Argandoña, Guillermo y otro con Empresa de los Ferrocarriles del Estado, 2015, cons. 11). Razón por la cual, concluyó que el delito sí se encontraba acreditado, ya que su autor "...es un sujeto cualificado vinculado a la Administración Pública...". (Morgan Argandoña, Guillermo y otro con Empresa de los Ferrocarriles del Estado, 2015, cons. 11) y su estatuto administrativo se encuentra integrado por la Ley Orgánica de cada empresa -la Ley $N^{\circ} 18.575$ (1986, art. 21, inc. 2), señala que las normas sobre organización y funcionamiento de los organismos que integran la Administración del Estado, no se aplicarán a las empresas públicas creadas por ley, las cuales se regirán por su respectiva ley de quórum calificado-, por las normas del Código del Trabajo (Dictamen $\left.N^{\circ} 24056,2008\right)$ y por lo señalado en la Ley $N^{\circ} 18.575$ (1986), esta última normativa, como se ha señalado, contempla una serie de principios básicos que son de aplicación directa y vinculantes para toda la Administración Pública, por lo que también resultan obligatorios en el caso que se deban aplicar estatutos especiales a organismos excluidos del Título II de la Ley 18.575 (1986), por ejemplo, el Código del Trabajo (Marín Vallejo,2000, p. 221).

Consecuencia de lo anterior, es que no se podrá aplicar a dichos trabajadores otros ordenamientos que regulen a funcionarios que se desempeñen en otras reparticiones del Estado, ya que su estatuto administrativo se aplica producto de un acto unilateral y potestativo de la autoridad estatal, y no en virtud a una convención celebrada entre trabajador y empleador. Ni siquiera podría proceder la aplicación de otros cuerpos legales por vía analógica, sobre la base de que todos son funcionarios públicos, toda vez que para su procedencia se requiere que una situación similar a aquella que se encuentra normada por ley, carezca de regulación (Squella Narducci, 2000, p. 486), y en este caso la relación laboral de los trabajadores de empresas estatales sí se encuentra normada, lo que ocurre es que su regulación se realiza por un ordenamiento jurídico distinto al de otros agentes públicos, cual es la legislación particular de cada empresa y el Código del Trabajo, razón por la cual, solo procede la aplicación de las instituciones contenidas en estos cuerpos normativos.

Por ejemplo, no se podría otorgar a estos funcionarios la posibilidad de hacer uso de días de permiso con goce de remuneraciones, porque dicha figura se encuentra regulada en la Ley $N^{\circ} 18.834$ (1989) y no en el Código laboral (Dictamen $N^{\circ} 36106$, 2009); tampoco la oportunidad de desempeñarse en otros organismos públicos, en virtud de una comisión de servicio, ya que ésta última se contempla en cuerpos nor- 
mativos que no conforman su estatuto administrativo (Dictamen No 19940, 2006). La excepción, es que el estatuto administrativo de alguna empresa pública en particular contemple una institución que sea aplicable a otros agentes públicos, por ejemplo, las leyes orgánicas de las empresas castrenses permiten que funcionarios de las fuerzas armadas se puedan desempeñar en dichos organismos empresariales, puede consultarse la Ley $N^{\circ} 18.296$ (1984, art. 15), la Ley $N^{\circ} 18.297$ (1984, art. 11) y el Decreto № 375 (1979, art. 13), que fija el texto de la ley Orgánica de la Fábrica y Maestranza del Ejército

Como se puede observar, la regulación a la cual se encuentran sujetos los trabajadores de empresas estatales, genera un régimen de derechos y obligaciones distinto de aquél que regula a los empleados del sector privado. Este resultado se explica, primero, porque su vinculación con el Estado es más estrecha que aquella que se produce entre privados regulados por el mismo código laboral (Bermúdez Soto, 2014 , p. 435). Segundo, ya que en la actividad a reglamentarse predomina un interés general por sobre el interés del funcionario, (Silva Cimma y Verdugo Lay, 1993, p. 113), no obstante, estar regulados por el mismo código laboral; y diferente también del resto de la Administración Pública, a pesar de su condición de funcionarios públicos. En este contexto de parcialidad, resulta interesante analizar tres derechos colectivos cuya procedencia, al menos, es discutida con respecto a otros agentes estatales, pero que sí proceden tratándose de los trabajadores particulares, cuales son: la sindicalización, la negociación colectiva y la huelga.

\subsection{Derecho a la sindicalización}

Todos los trabajadores que se desempeñan al interior de las empresas públicas, incluidos los que laboran en aquellas dependientes del Ministerio de Defensa Nacional o que se relacionen con el gobierno a través de dicha Secretaría de Estado, son titulares del derecho a constituir las organizaciones sindicales que estimen convenientes, sin autorización previa y con la sola condición de sujetarse a las disposiciones legales.

Esta afirmación se fundamenta en el Código del Trabajo (2003, arts. 212 y 217) y en algunas leyes orgánicas de estos organismos en particular, por ejemplo, la Ley No 19.132 (1992, art. 30), que crea a la Empresa Televisión Nacional de Chile, señala cuales son los trabajadores que tendrán derecho a participar en las organizaciones sindicales, y el Decreto Ley No 2.079 (1978, art. 45), Ley Orgánica del Banco del Estado, hace referencia a la organización sindical de sus trabajadores. Además, ha sido reiterada por el órgano contralor, al señalar que en las empresas del Estado "...no pueden existir otras organizaciones de trabajadores que no sean sindicatos..." (Dictamen N7964, 1980), es decir, no puede existir en una empresa estatal una asociación de funcionarios u otra agrupación de trabajadores, como ocurre en organismos regidos por estatutos administrativos distintos al código laboral, de conformidad con la 
Ley $N^{\circ} 19.296$ (1994), que Establece Normas sobre Asociaciones de Funcionarios de la Administración del Estado, por tanto, respecto de los organismos regidos por esta última disposición no procede el derecho a constituir sindicatos. El fundamento de tal exclusión, es que dichas organizaciones impedirían la primacía del interés general y potenciarían el interés individual de los funcionarios públicos (Silva Cimma y Verdugo Lay, 1996, p. 77). Sin embargo, se ha contra argumentado a favor del derecho de los agentes públicos a constituir sindicatos, sobre la base que el interés de la comunidad se centra en el respeto a la igualdad y satisfacción de las necesidades de sus integrantes, sin importar quienes sean, por lo que no deberían existir distingos en cuanto a los derechos de los trabajadores, sean públicos o privados (Gamonal Contreras, 2011, pp. 159-160).

Por tanto, los trabajadores de las veinte empresas del Estado tienen derecho a sindicalizarse, a fin de que tales organizaciones puedan representarlos en las instancias de negociación colectiva que corresponda, en el ejercicio de sus derechos ante la empresa y para todos los otros fines que les señale la ley. Un ejemplo del derecho de los trabajadores de empresas del Estado para constituir sindicatos y su protección, puede encontrarse en la sentencia de la Corte Suprema del 26 de enero de 1993 (cons. 3 y 4), a través de la cual se acogió un recurso de protección interpuesto en contra de la Corporación Nacional del Cobre por prácticas antisindicales. Los hechos consistieron en la decisión de la empresa de crear una nueva división empresarial, en virtud a su facultad para establecer oficinas, agencias y unidades de servicio con administración independiente, lo cual traía como consecuencia, a juicio de la empresa, que los trabajadores de esta nueva unidad administrativa ya no podrían seguir afiliados a los sindicatos de divisiones anteriores, lo que obligaba a la desafiliación aun en contra de su voluntad. La Corte señaló que el acto de la empresa constituía una amenaza para los derechos sindicales, ya que representaba un hecho de fuerza física o moral en los trabajadores con el objetivo de obtener su afiliación o desafiliación a un sindicato respectivo.

\subsection{Derecho a la negociación colectiva}

No obstante, lo expuesto, una situación distinta podría ocurrir a propósito del derecho a la negociación colectiva, es decir, que no todos los funcionarios que laboran al interior de empresas públicas tengan derecho para establecer condiciones comunes de trabajo y de remuneraciones. Antes de entrar en dicho análisis, se debe dejar establecido que el principio general es el que emana de la Constitución Política (2005), es decir, que la negociación colectiva es "...un derecho de los trabajadores, salvo los casos en que la ley expresamente no permita negociar" (art. 19, 16, inc. 4). Por tal razón, el Decreto que Establece Normas sobre Negociación Colectiva, facultó al Presidente de la República para modificar el régimen jurídico de las empresas del Estado, con el "...exclusivo objeto de que puedan someterse a las disposiciones de esta 
ley..." (Decreto Ley № 2.758, 1979, art. 14 transitorio), a saber, para que pudieran vincularse a las normas que rigen las condiciones comunes de trabajo.

Es así como se dictan el Decreto con Fuerza de Ley № 1 (1979) y Decreto con Fuerza de Ley № 3 (1980), que autorizan a la Empresa Nacional de Minería, del Petróleo, al Banco del Estado y a la Empresa de Ferrocarriles para negociar colectivamente, y la Ley $N^{\circ} 19.279$ (1993) que hace lo mismo respecto de Correos de Chile.

Además, existen textos orgánicos que, expresamente, confieren dicha posibilidad a sus trabajadores, por ejemplo, el caso de la Corporación Nacional del Cobre (Ley $\left.N^{\circ} 1.350,1976\right)$, cuyo artículo 25 señala que sus funcionarios estarán sometidos a las normas sobre negociación colectiva que rijan para las empresas del sector privado.

Por el mismo mandato constitucional, es que cuando no se permite dicha negociación existen disposiciones que así lo señalan, por ejemplo, el Código del Trabajo (2003, art. 304) que excluye a los funcionarios que laboran en las empresas castrenses de la posibilidad de negociar colectivamente. Por tanto, tal derecho, salvo que exista prohibición legal, procede respecto de la generalidad de las empresas públicas.

Volviendo al cuestionamiento planteado, cuál era la posibilidad que la negociación colectiva no proceda respecto de todas o de algunas empresas estatales, se debe señalar que es este último artículo 304 la fuente que da origen a dicha interrogante.

En efecto, esta disposición no permite la negociación colectiva en las empresas públicas o privadas cuyos presupuestos, en cualquiera de los dos últimos años calendario, hayan sido financiados en más de un $50 \%$ por el Estado directamente o a través de derechos o impuestos. Es decir, la norma comprende un supuesto en el cual se podrían circunscribir a las empresas estatales y excluir a sus funcionarios de la posibilidad de negociar colectivamente, cual es que el financiamiento del organismo empresarial haya provenido en más de un $50 \%$ del poder estatal.

Para saber si concurre tal excepción, primero se debe establecer su sentido.

Al respecto, la jurisprudencia judicial ha señalado que la expresión "...cuyos presupuestos, en cualquiera de los dos últimos años calendarios, hayan sido financiados en más de un 50\% por el Estado..." (Código del Trabajo, 2003, art. 304), lo que busca es

...excluir de la negociación colectiva a aquellas empresas financiadas con fondos públicos en forma directa o indirecta, pero sobre las cuales exista una previsión de su financiamiento basal a través de esta forma (...) Por ende, si el sujeto que recibe aportes del Estado (...) lo hace en base a la realización de prestaciones que importan un desembolso en dineros públicos para su reali- 
Empresas del Estado y su vinculación al Derecho Público Chileno en materia laboral.

zación, no puede ser considerado dentro de la excepción... (Edermira Rapiman Pichunla con Dirección Regional del Trabajo, 2011, cons. 12).

Es decir, el supuesto que contempla el artículo 304, solo procede si la entrega de fondos públicos a la empresa es a título gratuito, y se justifica en la existencia de un régimen convencional o legal que regule dicho traspaso. Consecuentemente, no procedería si el organismo empresarial tuviera que efectuar alguna contraprestación, en bienes o servicios, por los aportes recibidos (Ordinario $N^{\circ} 3356 / 50,2014$ ).

Por tanto, para saber si concurre la excepción, habrá que estarse a lo que dispongan las leyes orgánicas de las empresas estatales, las de presupuesto del sector público y aquellas que les efectúen aportes de capital, a fin de conocer la causa y el monto total financiado por el Estado. Si del análisis se desprende que la suma entregada es superior en un $50 \%$ y a título gratuito, se configuraría la excepción a la posibilidad de negociar colectivamente.

En el evento que lo anterior ocurra, el momento para invocar la exclusión es, paradójicamente, durante el proceso de negociación colectiva, específicamente en el trámite de la respuesta establecido en el Código del Trabajo (2003, art. 329), en razón de que el financiamiento de la empresa es una situación de hecho que deberá evaluarse en cada caso (Ordinario № 3069/153, 2001 y Ordinario № 2854, 2014). Luego, le corresponderá al propio organismo estatal, específicamente a sus órganos encargados de la dirección y administración, manifestar que se encuentra en la situación descrita en el artículo 304, a fin de que la eventual exclusión sea resuelta por la autoridad competente, es decir, por el Inspector o Director del Trabajo respectivo.

Por último, se hace presente que los recursos con los cuales negociará la empresa son de carácter público, por tanto, debe observar las instrucciones impartidas por el Ministerio de Hacienda, contenidas en la ya citada Circular № 15 (2018) de dicha Secretaría Ministerial (En este documento, se actualizan instrucciones y procedimientos respecto a la negociación colectiva y política de personal para empresas del Estado. Su número 4 señala que los costos totales del nuevo contrato colectivo, producto de la negociación que se lleve a cabo, no podrán exceder de un $1 \%$ real del promedio anual respecto del contrato colectivo vigente, porcentaje que debe estar asociado a incrementos efectivos de la productividad de la empresa, de lo contrario, solo deben mantenerse los costos laborales en términos reales. Se agrega, que el financiamiento de la negociación colectiva no debe afectar el traspaso de utilidades al Fisco, programado en el presupuesto vigente y/o estratégico de la empresa), debido a que estos recursos no son de propiedad de los órganos directivos del ente empresarial, sino que son de origen y destino público. 


\subsection{El derecho a huelga en las empresas del Estado}

El último aspecto que corresponde analizar, es si los trabajadores de las empresas del Estado son titulares del derecho a interrumpir la actividad laboral.

Como se sabe, la huelga se encuentra consagrada en la Constitución Política $(2005$, art. 19, 16) por vía de exclusión - Los redactores de la actual Constitución no quisieron consagrar el derecho a huelga de manera expresa debido a las diferencias de opinión respecto de su naturaleza, ya que no se la consideraba como un derecho sino que como una solución de fuerza, razón por la cual, solo se limitaron a señalar en qué casos está prohibida, es decir, se refirieron a ella como un hecho cuya procedencia es admitida respecto de las situaciones en que no está prohibida, Silva Bascuñán (2010, pp. 304 y 305)-, es decir, el constituyente la prohíbe respecto de determinados funcionarios, cuales son los del Estado y de las Municipalidades, tal prohibición se encuentra consagrada, además, en el Estatuto Administrativo, al indicar que el funcionario público estará afecto a las siguientes prohibiciones: "...dirigir, promover o participar en huelgas, interrupción o paralización de actividades, totales o parciales..." (Decreto con Fuerza Ley $N^{\circ} 29,2005$, art.84, i), y los que trabajen en corporaciones o empresas que atiendan servicios de utilidad pública o cuya paralización cause grave daño a la salud, a la economía del país, al abastecimiento de la población o a la seguridad nacional.

El Código del Trabajo (2003, art. 362) reitera la norma constitucional, agregando que le corresponderá a los Ministerios del Trabajo y Previsión Social, Defensa Nacional y Economía, Fomento y Turismo efectuar la calificación de encontrarse la empresa en alguna de dichas situaciones. Al respecto, puede consultarse la Resolución Exeenta № 173, del 29 de agosto de 2019, que califica y determina las empresas o corporaciones cuyos trabajadores no podrán ejercer el derecho a huelga, conforme a lo dispuesto por el artículo 362 del Código del Trabajo. Por tanto, se ha entendido que, como derecho fundamental, procede respecto de todos los trabajadores restantes (Tapia Guerrero, 2005, p. 205). Sin embargo, también existen opiniones en contrario, es decir, que consideran al derecho fundamental de huelga reconocido de manera expresa en la Constitución Política pero contenido en la libertad sindical. Por tanto, al reconocerse a esta última se estaría admitiendo la huelga por ser consustancial al derecho a constituir sindicatos. Conclusión reforzada por la tesis que postula que la huelga forma parte de un bloque de constitucionalidad como derecho fundamental, en razón de que éstos no pueden reducirse solo a aquellos expresamente regulados en la Carta Fundamental (Gamonal Contreras, 2013, p. 122).

En este contexto, la pregunta que surge es si los trabajadores de las empresas estatales son titulares del derecho a huelga o, por el contrario, se encuentran en algunas de las situaciones de exclusión. Este cuestionamiento surge por la concurrencia simultánea de dos variables aparentemente opuestas entre sí. La primera, es que 
Empresas del Estado y su vinculación al Derecho Público Chileno en materia laboral.

tales funcionarios se desempeñan es un organismo estatal. La segunda, es que, no obstante ello, se encuentran regulados por el Código del Trabajo, normativa que reconoce y regula el derecho a huelga.

A este respecto, lo primero que se debe señalar es que cuando el texto constitucional utiliza la expresión los funcionarios del Estado y de las municipalidades, no efectúa ningún tipo de distinción respecto del organismo estatal al cual se está refiriendo, tampoco especifica un ente público en particular o excluye a algún servicio, empresa, juntas, consejos etc. que tenga dicha calidad, simplemente hace alusión al Estado. Lo mismo a propósito del régimen legal al cual se encuentren sometidos los trabajadores, simplemente se refiere a los funcionarios estatales, sin distinguir el estatuto jurídico que regula sus relaciones laborales con el Estado.

Por tanto, frente a la amplitud de la norma, cabe concluir que el constituyente, al prohibir el derecho a huelga respecto de los funcionarios del Estado, está haciendo extensiva dicha prohibición a todos los trabajadores estatales, independiente del ente en el cual laboren y del estatuto que los rija. En consecuencia, a los trabajadores de las empresas públicas les estaría vedado el derecho a huelga, toda vez que, como se ha indicado, laboran en un organismo del Estado y son funcionarios estatales, lo cual es transversal y predominante con respecto a su estatuto laboral de derecho común. Concluir lo contrario, fundamentado en que se encuentran regidos por el Código del Trabajo, significaría obviar la calidad estatal de dichos organismos e ir en contra del texto constitucional.

Lo anterior, se confirma con los antecedentes históricos que dieron origen a la expresión constitucional los funcionarios del Estado. En efecto, cuando la Comisión de Estudio de la Nueva Constitución se abocó a la tarea de redactar el actual artículo 19 № 16 inciso final de la Carta Fundamental, buscaba comprender en un solo concepto todos aquellos casos en los cuales no procede la suspensión del trabajo, es decir, su objetivo era lograr una normativa que actuara como síntesis. Por tal motivo, es que la actual prohibición constitucional, referida al sector público, pretende englobar a todas las instituciones que sean expresiones estatales, vale decir, a "...las diversas maneras en que se puede ser funcionario del Estado, sin entrar en detalle de lo que se entiende por tal, hoy día, de acuerdo con la estructura de la legislación chilena". (Actas Oficiales de la Comisión Constituyente Sesión 182a, 1976, p. 843). Específicamente, fue el comisionado Guzmán quien planteó esta norma como comprensiva de todos los casos en los cuales no procede el derecho a huelga, el texto, inicialmente propuesto, señalaba que:

'en ningún caso podrán declararse en huelga los funcionarios del Estado o de las municipalidades, como tampoco las personas que trabajen en empresas que atiendan servicios de utilidad pública o cuya paralización causaría grave daño a la salud, al abastecimiento de la población, la economía del país o la 
seguridad nacional'. (Actas Oficiales de la Comisión Constituyente Sesión 182a, 1976, p. 845 y 849 ).

Refuerza la prohibición de huelga respecto de los trabajadores de empresas públicas, los tradicionales argumentos que se han esgrimido para negar tal derecho al sector público en general, sintetizados en que la paralización de labores quebrantaría el principio de continuidad de la función pública (Cea Egaña, 2012, p. 473) y perjudicaría el interés público que justificó la creación del organismo respectivo. Otros fundamentos que se han esgrimido, para negar el derecho a huelga a los funcionarios estatales, son: la primacía del interés general, por lo que existiría una contradicción entre dicho interés y el particular de los trabajadores; la naturaleza estatutaria de la relación de empleado público, por lo que los funcionarios no tendrían la posibilidad de negociar nuevas o mejores condiciones de trabajo; la supremacía del poder estatal, la esencialidad de los servicios públicos y la negación del conflicto, en razón de que en la relación laboral pública no podrían existir intereses antagónicos, porque ambos, el Estado y sus funcionarios, deben velar para la satisfacción de necesidades colectivas, por lo mismo, no existiría la dicotomía capital-trabajo (Varas Marchant, 2015, pp. 57 a 60). Estos argumentos se basan en la teoría clásica, según la cual la relación jurídica del funcionario público surge de la ley, en contraposición a la teoría contractualista, que acepta una voluntad y capacidad para negociar del ente público y del funcionario (Ortega Álvarez, 1983, p. 29). A mayor abundamiento, cabe señalar que las leyes orgánicas de las empresas estatales no señalan, en términos específicos, que procede el derecho a huelga respecto de sus trabajadores, como sí sucede a propósito de los derechos de sindicalización y negociación colectiva, según lo ya visto.

El problema de la huelga en las empresas del Estado es que se está en presencia de un ente cuya actividad se considera necesaria para el interés público, por lo que su paralización podría perjudicar a todos aquellos que se benefician, directa o indirectamente, con dicha actividad (Cassagne, 2003, pp. 171 a 173). Por ejemplo, una huelga en la Empresa de Ferrocarriles del Estado implicaría obstaculizar el traslado a un sector importante de la población; una huelga en Correos de Chile significaría la imposibilidad de comunicación o de envío de encomiendas, y una paralización de las funciones del Banco del Estado acarrearía la imposibilidad del acceso a recursos financieros.

No obstante lo expuesto, no se debe obviar que existen tratados internacionales, ratificados por Chile, que con la misma claridad que el texto constitucional reconocen a la huelga como derecho fundamental y, además, la hacen extensiva al sector público, permitiendo restricciones solamente en aquellos servicios esenciales en un estricto sentido del término. A través del Comité de Libertad Sindical y la Comisión de Expertos en Aplicación de Convenios y Recomendaciones, y en virtud de los Convenios Internacionales $N^{\circ} .87$ (1950) y No 151 (1981), se ha llegado a la conclu- 
Empresas del Estado y su vinculación al Derecho Público Chileno en materia laboral.

sión de que los funcionarios públicos son titulares del derecho a negociar colectivamente y del derecho a huelga, salvo limitaciones muy particulares, (Hernáez CasasCordero, 2017, pp. 72 y 82). Por ejemplo, el artículo 8 letra d) del Pacto Internacional de los Derechos Económicos, Sociales y Culturales (1976), que expresamente reconoce la obligación de los Estados partes de garantizar el derecho a huelga. Este reconocimiento y compromiso adoptado con respecto a tal derecho, genera el problema de tener que articular las disposiciones internacionales con la normativa constitucional interna relacionada con la huelga, específicamente con aquella que la prohíbe tratándose de trabajadores estatales, dentro de los cuales se comprenderían a los que laboran al interior de una empresa pública.

A este respecto, cabe señalar que la evolución que ha experimentado la interpretación de tratados internacionales sobre derechos humanos, cuando ha existido una eventual contradicción con la normativa interna de cada Estado, ha ido desde una postura que restringe su objeto, es decir, que no hace extensivo sus efectos por considerar que ello podría constituir una derogación a la soberanía estatal, hasta llegar a una interpretación teleológica, que coloca el énfasis en la realización de la esencia del tratado y no en los intereses individuales de las partes contratantes (Aldunate Lizana, 2008, pp. 125-127).

Si se adopta esta última postura, a fin de solucionar el conflicto normativo entre los tratados internacionales, que reconocen a la huelga como un derecho, y la normativa interna que la prohíbe tratándose de funcionarios del Estado, dentro de los cuales, se reitera, estarían los que laboran en empresas públicas, habría que concluir que la procedencia de tal derecho con respecto a estos funcionarios sí procede, o, por lo menos, es discutida.

En efecto, lo primero que se debe señalar, es que se está en presencia de trabajadores que si bien se desempeñan en un organismo estatal, la actividad de éste no responde a aquellas de carácter esencial para la colectividad, como lo sería la desplegada por un servicio de salud o por un ente monopolizado por el Estado, el Comité de Libertad Sindical ha señalado que "la prohibición de huelga solo podría ser aceptable, con respecto a los funcionarios públicos, que ejercen funciones de autoridad en nombre del Estado o con respecto de los trabajadores de los servicios esenciales en el sentido estricto del término", definiendo a estos últimos como "aquellos cuya interrupción podría poner en peligro la vida, la seguridad o la salud de la persona en todo o parte de la población", (citado por Zúñiga Urbina, 2015, p. 175). En la misma línea, la jurisprudencia ha señalado que el límite a la huelga "...está dado únicamente cuando se afecten servicios destinados a satisfacer derechos fundamentales, libertades públicas y bienes constitucionalmente protegidos, tales como la vida, la salud y la satisfacción de necesidades básicas de la persona..." (Actionline Chile S.A. con Claudio Yutronic Rojas y otro, 2015, cons. 5). Por el contrario, las empresas públicas producen bienes u otorgan servicios que colocan en el mercado, por lo que el usuario dispone, al menos en teoría, 
de distintas posibilidades para satisfacer una necesidad, en efecto, se está en presencia de una gestión económica del Estado, tanto por su objeto como por su frecuencia, por lo que excede la consideración clásica del servicio público, más aun si se toma en cuenta que la gestión de la empresa se realiza por medio de técnicas económicas, no por un procedimiento de derecho público, Bassols Coma (1977, pp. 36 y 46). Esta competencia, propia de la actividad económica, le restaría el carácter de esencialidad al actuar de la empresa, por tanto, no podría revestir la misma importancia la interrupción de un servicio público, propiamente tal, con aquella producida en una empresa pública, porque en este último supuesto no existe una relación directa entre el organismo y el destinatario del bien, solo existirá en el evento que el particular opte por el ente estatal (Ariño Ortiz, 1993, pp. 297-298).

Segundo, no se debe olvidar que fue el propio constituyente quien ordenó, que en el evento de que el Estado desarrolle actividades empresariales, éstas “...estarán sometidas a la legislación común aplicable a los particulares..." (Constitución Política de la República de Chile, 2005, art. 19, no. 21, inc. 2), y dicha legislación común, en materia laboral, es el Código del Trabajo (2003), normativa que reconoce y regula el derecho a huelga dentro de la negociación colectiva, último derecho que, como se señaló, procede respecto de la generalidad de las empresas del Estado creadas por ley.

Por tanto, si se está frente a la disyuntiva de extender o no el derecho a huelga respecto de trabajadores que se desempeñan en un servicio no esencial en términos clásicos, y que se encuentran regulados por la misma normativa que se aplica al resto de las empresas que concurren en el ámbito económico, una interpretación actual de los tratados internacionales sobre derechos humanos obliga a hacer extensivo tal derecho a los funcionarios de empresas públicas, puesto que al ser un derecho fundamental (Ugarte Cataldo, Varas Marchant y Aravena Araneda, 2016, pp. 101 y 102) impone una interpretación que ensanche su funcionalidad protectora, no que la restringa. Esta posición, además, se encuentra en concordancia con el origen histórico de los derechos fundamentales, cual era ser una respuesta a situaciones concretas de opresión y arbitrariedad, y se concilia con directrices específicas de interpretación contenidas en tratados en particular, por ejemplo, la Convención Americana sobre Derechos Humanos (1978, art. 29, d), que prohíbe una interpretación que limite o excluya los efectos que pueda producir la Declaración Americana de los Derechos y Deberes del Hombre de 1948 (Aldunate Lizana, 2008, pp 110 y 129).

Esta postura extensiva en la interpretación de los derechos esenciales ha sido, precisamente, la adoptada por el Tribunal Constitucional (2009) en sentencia $\mathrm{N}^{\circ}$ 1361-2009, cuando ha debido enfrentarse a la misma disyuntiva. El órgano de control, invocando el principio pro homine o favor libertatis, ha señalado que si se está frente a la alternativa de extender o limitar un derecho fundamental, "...se ha de escoger la que restringe en menor escala el derecho protegido...'debe prevalecer la norma 
Empresas del Estado y su vinculación al Derecho Público Chileno en materia laboral.

más favorable a la persona humana'" (cons. 73, citando al visto 66 de la STC, Rol № 740 de 2008, que a su vez cita a la Opinión consultiva del 13 de noviembre de 1985 de la Corte Interamericana de Derechos Humanos, n. 52). Actitud que, además, estaría acorde con lo dispuesto en el artículo 5 inciso segundo de la propia Carta Fundamental.

A mayor abundamiento, a fin de reconocer el derecho a huelga a los trabajadores de empresas estatales, valga señalar el cada vez mayor traspaso, desde el sector privado al público, de instituciones propias del Derecho Social (Silva Cimma y Verdugo Lay, 1993, pp. 45 a 53; Gamonal Contreras, 2011, pp. 164 y 165; Hernáez Casas-Cordero, 2017, p. 76), como lo es la protección de los derechos fundamentales de los funcionarios públicos a través del procedimiento de tutela laboral regulado en el Código del Trabajo, no obstante, no estar regidos por esta última normativa; y la propia realidad de los hechos, al ser de público conocimiento las reiteradas paralizaciones o interrupciones de actividades, por parte de trabajadores de empresas estatales, justificadas en la regulación de derecho común que les asiste.

Si bien en un primer momento el máximo tribunal negó la posibilidad de que los Juzgados del Trabajo pudieran conocer de las acciones de tutela entabladas por funcionarios públicos, hoy es prácticamente uniforme su criterio en orden a decretar que sí resulta aplicable dicho procedimiento respecto de funcionarios estatales, fundándose en la inexistencia de una regulación específica en los estatutos que regulan la función pública, que la relación entre Estado y funcionarios es de carácter laboral y que, por lo mismo, la acción de protección no es la vía idónea para proteger una vulneración de garantías fundamentales con respecto a dichos trabajadores (Bravo Peña y Zamora Picciani, 2019, p. 39). Así, la Corte Suprema ha señalado que:

...no existe impedimento para aplicar las normas de tutela a los funcionarios de la Administración del Estado, en la medida que su ámbito de aplicación abarca o comprende a todos los trabajadores sin distinción, calidad que, como se dijo, también poseen los referidos funcionarios. (Lorena Montero Lueyza con Fisco de Chile, 2019, cons. 4)

Lo mismo se expresa en Tudesca con Fisco (2019, cons. 11, 15 y 16).

Por lo mismo, es que no solo se comparte la opinión de un sector importante de la doctrina que reconoce la necesidad de garantizar el derecho a huelga de todos funcionarios públicos (Morales Espinoza, 2008, p. 588; Gamonal Contreras, 1998, p. 84; Hernáez Casas-Cordero, 2017, pp. 76 y 77; y Román Cordero, 2018, p. 69), sino que, y con mayor razón, se hace extensivo tal requerimiento para los trabajadores que laboran en una empresa estatal. Sin olvidar, que si bien tales organismos no realizan una prestación esencial en un sentido clásico, en ellos sí subyace un interés público de tal relevancia que justificó la intervención del Estado en un área reconocida como fundamental de las personas, cual es la libertad de empresa. 
Por lo demás, la titularidad del derecho a huelga respecto de trabajadores de empresas estatales, se refleja de manera concreta e indiscutida en la Corporación del Cobre.

En efecto, primero se debe reiterar lo expuesto a propósito del derecho a negociación colectiva de que son titulares los trabajadores de esta empresa estatal, de conformidad con el Decreto Ley № 1.350 (1976, art. 25), que hace extensivas a Codelco las normas sobre organización sindical y negociación colectiva que rijan para las empresas del sector privado. Normativa complementada con el Decreto Ley № 434 (1979) y el Decreto $N^{\circ} 110$ (2012), que le otorgan el carácter de empresa a las divisiones mineras de dicha entidad para efectos de la negociación colectiva.

De conformidad con los artículos primeros de dichos cuerpos normativos, estas divisiones son: Chuquicamata, El Salvador, Andina, el Teniendo, Oficina Central, Ventanas, Ministro Hales, Radomiro Tomic y Gabriela Mistral. Se hace presente en este punto, un pronunciamiento de la Corte Suprema que rechazó un Recurso de Protección interpuesto por la Corporación Nacional del Cobre en contra de la Inspección Provincial del Trabajo, fundamentado en que éste último organismo habría obligado a la empresa estatal a incorporar en el proceso de negociación colectiva, llevado por la división Chuquicamata, a trabajadores que se desempeñaban en las unidades Radomiro Tomic y Ministro Hales. El máximo Tribunal señaló que como éstas dos últimas divisiones no tienen el carácter de empresa por no estar incorporadas en el Decreto Ley $N^{\circ} 434$ (1979), no cumplen con los requisitos para negociar colectivamente, razón por la cual sus trabajadores deberán formar parte del proceso de negociación colectiva de la división Chuquicamata. (Corporación Nacional del Cobre con Inspección Provincial del Trabajo el Loa, 2012, cons. 9). No obstante el razonamiento de la Corte, se hace presente que por aplicación del Decreto Ley 1.350 (1976, art. 1), la primera norma que debe aplicarse, a fin de regular el funcionamiento de Codelco, es, precisamente, este Decreto Ley, que señala "Cada una de las Divisiones Operativas que conforman la empresa, confeccionarán anualmente un balance económico financiero (...) para todos los efectos de la negociación colectiva" (Decreto Ley 1.350, 1976, art. 12). Por tanto, si Radomiro Tomic y Ministro Hales son divisiones operativas de Codelco, es con dichas unidades con quienes los respectivos trabajadores deben realizar el proceso de negociación colectiva, independiente de lo dispuesto en el Código del Trabajo (2003, art. 304) y de la actitud del ejecutivo. Por lo demás, no se debe olvidar que las empresas del Estado solo pueden surgir a la vida jurídica por medio de ley de quórum calificado, cuerpo normativo que debe contemplar todos los aspectos de la empresa y que constituye su principal fuente de regulación, Dictamen $\mathrm{N}^{\circ} 2601$ (1996) y No 39562 (1997).

Dicho lo anterior, y volviendo al tema específico sobre el derecho a huelga respecto de la Corporación Nacional del Cobre, valga señalar que, de conformidad a la Constitución Política (2005), "La gran minería del cobre y las empresas consideradas 
Empresas del Estado y su vinculación al Derecho Público Chileno en materia laboral.

como tal, en virtud a lo prescrito en la $17^{a}$ disposición transitoria de la Constitución Política de 1925, continuarán rigiéndose por las normas constitucionales vigentes a la fecha de promulgación de esta Constitución" (Disposición transitoria, 3). Las normas constitucionales que se mantenían vigentes a la fecha de promulgación de la actual Carta Fundamental, y que regían a la gran minería del cobre y a las empresas nacionalizadas, son las disposiciones 17, 22 y 23, todas transitorias del texto político de 1925 (Decreto con Fuerza de Ley $N^{\circ} 1.333,1971$ ).

La disposición, en el inciso segundo de su letra k), señalaba que los trabajadores del cobre "... seguirán gozando de los derechos de sindicalización y huelga que el actual Estatuto les confiere, conforme a las modalidades y condiciones establecidas en él" (Decreto con Fuerza de Ley № 1.333, 1971, Disposición transitoria 17, k). Este Estatuto se contenía en el Decreto No 307 (1970), y permitía, expresamente, la posibilidad de huelga, señalaba que:

Rechazada por los trabajadores la fórmula de solución superior sometida a su decisión se entenderá aprobada la huelga.

Si la fórmula de solución propuesta por el o los mediadores o por la Junta actuando en esta calidad fuere aceptada por los trabajadores y rechazada por la empresa, se entenderá prorrogado el plazo para hacer efectiva la huelga por diez días, al término de los cuales los trabajadores podrán paralizar sus faenas, si no se hubiere logrado un acuerdo dentro del plazo referido. (art. 33)

Por tanto, de conformidad con el estatuto jurídico que regulaba las relaciones laborales de la actividad minera antes del proceso de nacionalización de la gran minería, el derecho a huelga se encontraba expresamente regulado y permitido en el estatuto que regía a sus trabajadores. Si se considera lo dispuesto en la disposición $17^{\text {a }}$ transitoria de la Carta Política de 1925 que, se reitera, señalaba que los trabajadores de la gran minería seguirían gozando del derecho a huelga que su estatuto les confería, se debe concluir, primero, que éste se mantuvo después del proceso de nacionalización, $y$, segundo, que se conserva en la actualidad, toda vez que de conformidad al artículo tercero transitorio de la actual Carta Fundamental, la gran minería del cobre se rige por las normas constitucionales vigentes a la fecha de promulgación de la actual Constitución, y una de esas normas vigentes es la disposición 17a transitoria que, como se ha señalado, garantiza a los trabajadores que, no obstante el proceso de nacionalización, éstos seguirán gozando del derecho a huelga.

Es más, esta misma normativa señala que "Al dictar un nuevo Estatuto, el legislador, en caso alguno, podrá suprimir, disminuir o suspender los derechos o beneficios económicos, sociales, sindicales o cualesquiera otros que actualmente disfruten los trabajadores de las empresas de la Gran Minería del Cobre..." (Decreto con Fuerza de Ley $\mathrm{N}^{\circ} 1.333,1971$, Disposición transitoria,17, k) 
Por tanto, el derecho a huelga respecto de los trabajadores de la Corporación del Cobre se encuentra reconocido a nivel constitucional. Las normas contenidas en la anterior Carta Fundamental y que siguen rigiendo a la gran minería del cobre, se sitúan en el mismo nivel o paridad jerárquica que los artículos contenidos en el vigente texto político, por disponerlo así el propio constituyente en el actual artículo tercero transitorio (Cea Egaña, 1990, p. 278). Complementado con el Estatuto Orgánico de CODELCO (Decreto Ley $N^{\circ} 1.350,1976$, art. 25), que se refiere a la facultad del ejecutivo para efectuar la calificación contemplada en el inciso final del artículo 6 del Decreto Ley № 2.758 (1979), antecesor del actual Código del Trabajo (2003, art. 362), es decir, el Presidente de la República puede determinar que la Corporación Nacional del Cobre se encuentra en alguna de las situaciones previstas en dicha disposición y que impiden la declaración de huelga, por el daño que puede provocar a la población o a la seguridad nacional.

\section{Conclusiones}

El presente trabajo buscaba exponer el ámbito de aplicación del Derecho Público en las relaciones laborales que se producen en las empresas del Estado, desde el punto de vista de la empresa como empleadora y de sus trabajadores.

Respecto del organismo empresarial, se pudo observar que, no obstante estar regulados por el derecho común, se encuentran condicionados a principios públicos en sus relaciones laborales, lo cual produce, como consecuencia general, que las empresas del Estado no gocen de igual autonomía que un empleador privado, por el contrario, se encuentran sometidas a un especial modo de funcionamiento, caracterizado por la aplicación de principios constitucionales que rigen a la función pública.

A nivel particular, el protagonismo de estos principios se refleja en dos efectos: (i) en la selección del personal, toda vez que tales organismos, como empleadores, deberán observar los principios de igualdad en el acceso a los empleos públicos y el de objetividad al momento de definir el personal a contratar; y (ii) en la celebración del contrato de trabajo, ocasión en la cual es el principio de juridicidad el que destaca como factor determinante en la regulación de la actividad laboral de la empresa. En este punto, se destacó la problemática generada entre la autonomía financiera de estos organismos y el principio aludido, principalmente en lo que respecta a la celebración de pactos de contenido económico, señalándose que la aplicación de las normas sobre juridicidad no significa anular la autonomía de las empresas públicas, sino que la exigencia de un actuar proporcionado, que logre conciliar el interés público y el actuar laboral del organismo.

Con respecto a los trabajadores y los derechos colectivos, se pudo observar una innegable influencia de las normas de derecho común, en razón de estar regulados por su propio estatuto administrativo, representado en el Código del Trabajo, no 
obstante su calidad de funcionarios públicos. Esto permite que los trabajadores de las empresas estatales gocen, de manera indiscutida, de los derechos de sindicalización y negociación colectiva, al igual que en el sector privado. Con respecto a la posibilidad de huelga, se hizo presente que el texto constitucional, al prohibir tal derecho a los funcionarios del Estado, no distinguió en cuanto al órgano estatal en el cual éstos se desempeñan, lo que permitiría incluir en dicha prohibición a los trabajadores de empresas públicas. Sin embargo, también se hizo presente que una interpretación moderna de los tratados internacionales, sumado al carácter no esencial de estos organismos y a su normativa de derecho común, haría concluir que el derecho a huelga sí procede respecto de ellos, lo cual se reflejaría, a nivel real, en la Corporación del Cobre.

Como corolario de todo lo expresado, se puede señalar que en el resguardo al interés público que justifica la creación de estos organismos, actúa como un factor de aplicación del Derecho Público a la propia empresa actuando como empleadora, pero también justifica la intervención de normas de derecho laboral común, en lo que respecta a los derechos colectivos de sus trabajadores.

\section{Referencias Bibliográficas}

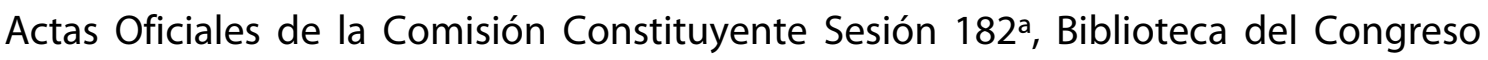
Nacional de La República de Chile, 14 de enero de 1976. Recuperado de https://bit.ly/305HDja

Actionline Chile S.A. con Claudio Yutronic Rojas y otro, Rol № 1144-2015 (Corte de Apelaciones de Santiago 23 de octubre de 2015). Recuperado de https://westlawchile.cl id: CL/JUR/6370/2015

Aldunate Lizana, E. (2008). Derechos fundamentales. Santiago: Legal Publishing.

Álvarez de la Rosa, M. (1987). El régimen jurídico de las incompatibilidades en los contratos de trabajo del sector público. Documentación administrativa, (210/211), 227-265. Recuperado de https://bit.ly/2S0hvSt

Ariño Ortiz, G. (1993). Economía y estado: Crisis y reforma del sector público. Madrid: Marcial Pons.

Ariño Ortiz, G., y López de Castro García-Morato, L. (2004). Principios de derecho público económico: (modelo de estado, gestión pública, regulación económica). Granada: Comares.

Aróstica Maldonado, I. (2001). Derecho administrativo económico. Santiago: Universidad Santo Tomás. 
Banco del Estado de Chile con Fisco, Rol N 6585-2007 (Corte Suprema 28 de mayo de 2009). Recuperado de https://bit.ly/3jFciM2

Barra Gallardo, N. (2004). Probidad administrativa (2a ed.). Santiago: LexisNexis.

Bassols Coma, M. (1977). Servicio público y empresa pública: reflexiones sobre las Ilamadas sociedades estatales. Revista de administración pública, 84, 27-60. Recuperado de https://bit.ly/3hQNgHS

Bravo Peña, N., y Zamora Picciani, R. (2019). La acción de la tutela laboral ante la jurisprudencia del Tribunal Constitucional y Corte Suprema. Revista laboral chilena, 279, 38-44.

Bermúdez Soto, J. (2014). Derecho administrativo general (3a ed.). Santiago: Legal Publishing.

Caldera Delgado, H. (1996). Crisis del dogma de la teoría del servicio público. Revista de derecho Público, (59). doi: 10.5354/0719-5249.1996.43305

Cassagne, J. C. (2003). Fragmentos de derecho administrativo: Entre la justicia, la economía y la política. Buenos Aires: Hammurabi.

Cea Egaña, J. L. (1990). Sobre la tercera disposición transitoria de la Constitución. Revista chilena de derecho, 17(2), 275-281. Recuperado de https://bit.ly/32TxEPN

Cea Egaña, J. L. (2012). Derecho constitucional chileno (2a ed., Vol. 2). Santiago: Universidad Católica de Chile.

CIMM Tecnologías y Servicios S.A. con Fisco de Chile y Contraloría General de la República, Rol N 1644-2008 (Décimo Séptimo Juzgado Civil de Santiago 29 de julio de 2010). Recuperado de https://bit.ly/3IIDdwQ

Circular $\mathrm{N}^{\circ} 15$. Actualiza instrucciones y procedimientos respecto de negociaciones colectivas y política de personal para empresas del Estado y aquéllas en que el Estado, sus instituciones o empresas tengan aporte de capital igual o superior al 50 por ciento. Ministerio de Hacienda, Gobierno de Chile, Santiago, Chile, 14 de septiembre de 2018. Recuperado de https://bit.ly/3jLoevL

Código Civil. Diario Oficial de la República de Chile, Santiago, Chile, 30 de mayo de 2000. Recuperado de http://bcn.cl/1 uqm8

Código del Trabajo. Diario Oficial de la República de Chile, Santiago, Chile, 16 de enero de 2003. Recuperado de http://bcn.cl/1uvqw

Constitución Política de la República de Chile. Diario Oficial de la República de Chile, Santiago, Chile, 22 de septiembre de 2005. Recuperado de http://bcn.cl/1 uva9 
Empresas del Estado y su vinculación al Derecho Público Chileno en materia laboral.

Convención Americana sobre Derechos Humanos (Pacto de San José), Organización de los Estados Americanos, San José, Costa Rica, 18 de julio de 1978. Recuperado de https://bit.ly/3ogz53i

Convenio $\mathrm{N}^{\circ}$ 87. Convenio sobre la libertad sindical y la protección del derecho de sindicación, 1948. Organización Internacional del Trabajo, 04 de julio de 1950. Recuperado de https://bit.ly/3diqx7a

Convenio $\mathrm{N}^{\circ}$ 111. Convenio sobre la discriminación (empleo y ocupación). Organización Internacional del Trabajo, 15 de junio de1960. Recuperado de https://bit.ly/3ILVq6W

Convenio $\mathrm{N}^{\circ}$ 151. Convenio sobre las relaciones de trabajo en la administración pública, 1978. Organización Internacional del Trabajo, 25 de febrero de 1981. Recuperado de https://bit.ly/3dgHcrp

Cordero Vega, L. A. (2015). Lecciones de derecho administrativo. Santiago: Thomson Reuters.

Corporación Nacional del Cobre con Inspección Provincial del Trabajo el Loa, Rol No 2197-2012 (Corte Suprema 14 de junio de 2012). Recuperado de https://bit.ly/34yW802

Cuétara Martínez, J. M. (1983). La actividad de la administración: lecciones de derecho administrativo. Madrid: Tecnos.

Declaración Americana de los Derechos y Deberes del Hombre. Comisión Interamericana de Derechos Humanos, Bogotá, Colombia, 1948. Recuperado de https://bit.ly/3iLOS6f

Decreto con Fuerza de Ley $\mathrm{N}^{\circ} 1$. Fija texto refundido, coordinado y sistematizado de la Ley orgánica de la Empresa de los Ferrocarriles del Estado. Diario Oficial de la República de Chile, Santiago, Chile, 03 de agosto de 1993. Recuperado de http://bcn.cl/2k3mt

Decreto con Fuerza de Ley $\mathrm{N}^{\circ}$ 10. Crea la empresa de correos de chile, dispone la constitución de TELEX Chile comunicaciones Telegráficas S. A. y pone término a la existencia legal del Servicio de Correos y Telégrafos a contar de la fecha que indica. Diario Oficial de la República de Chile, Santiago, Chile, 30 de enero de 1982. Recuperado de http://bcn.cl/2k3mr

Decreto con Fuerza Ley $N^{\circ} 29$. Fija texto refundido, coordinado y sistematizado de la Ley № 18.834, sobre Estatuto Administrativo. Diario Oficial de la República de Chile, Santiago, Chile, 16 de marzo de 2005. Recuperado de http://bcn.cl/2f8f2 
Decreto con Fuerza de Ley N 153. Crea la Empresa Nacional de Minería. Diario Oficial de la República de Chile, Santiago, Chile, 05 de abril de 1960. Recuperado de http://bcn.cl/2k3n2

Decreto con Fuerza de Ley N 1.333. Fija texto de la Constitución Política del Estado. Diario Oficial de la República de Chile, Santiago, Chile, 25 de octubre de 1971. Recuperado de http://bcn.cl/2lj3y

Decreto $N^{\circ} 110$. Amplía unidades productivas de la Corporación Nacional del Cobre de Chile que deberán negociar por establecimiento, complementando así el artículo primero del Decreto No434, de 1979. Diario Oficial de la República de Chile, Santiago, Chile, 20 de noviembre de 2012. Recuperado de http://bcn.cl/2kmzb

Decreto $\mathrm{N}^{\circ}$ 307. Fija texto definitivo del estatuto de los trabajadores del cobre. Diario Oficial de la República de Chile, Santiago, Chile, 27 de julio de 1970. Recuperado de http://bcn.cl/2llui

Decreto $\mathrm{N}^{\circ}$ 375. Fija texto refundido, coordinado y sistematizado del DFL. 223, de 1953, Ley Orgánica de las fábricas y maestranzas del Ejército. Diario Oficial de la República de Chile, Santiago, Chile, 15 de febrero de 1979. Recuperado de http://bcn.cl/2k3nm

Decreto $\mathrm{N}^{\circ}$ 434. Establece empresas en que el estado tenga aporte, participación o representación en que se debe negociar por establecimiento y fija fecha de primera negociación para dichas empresas o para sus establecimientos, y el plazo mínimo de duración de los correspondientes contratos colectivos. Diario Oficial de la República de Chile, Santiago, Chile, 16 de agosto de 1979. Recuperado de http://bcn.cl/2lujm

Decreto Ley $N^{\circ}$ 1.350. Crea la Corporación Nacional del Cobre de Chile. Diario Oficial de la República de Chile, Santiago, 28 de febrero de 1976. Recuperado de http://bcn.cl/2lkfu

Decreto Ley N ${ }^{\circ}$ 2.079. Fija texto de la Ley Orgánica del Banco del Estado de Chile. Diario Oficial de la República de Chile, Santiago, Chile, 18 de enero de 1978. Recuperado de http://bcn.cl/2ll1c

Decreto Ley N².758. Establece normas sobre negociación colectiva. Diario Oficial de la República de Chile, Santiago, Chile, 06 de julio de 1979. Recuperado de http://bcn.cl/2ll1h

Dictamen № 2601 (Contraloría General de la República 23 de enero de 1996). Recuperado de https://bit.ly/3jpwWyD

Dictamen № 7116 (Contraloría General de la República 14 de marzo de 2018). Recuperado de https://bit.ly/34FR5uO 
Empresas del Estado y su vinculación al Derecho Público Chileno en materia laboral.

Dictamen № 7846 (Contraloría General de la República 08 de marzo de 2017). Recuperado de https://bit.ly/2lawJm5

Dictamen № 7964 (Contraloría General de la República 19 de febrero de 1980). Recuperado de https://bit.ly/3lefCOm

Dictamen No 9008 (Contraloría General de la República 14 de abril de 1992). Recuperado de https://bit.ly/2Gw22Y0

Dictamen № 11574 (Contraloría General de la República 13 de marzo de 2006). Recuperado de https://bit.ly/3d9XVws

Dictamen № 12350 (Contraloría General de la República 15 de mayo de 1989). Recuperado de https://bit.ly/36Gjlem

Dictamen № 14944 (Contraloría General de la República 24 de junio de 1991). Recuperado de https://bit.ly/3d7AcNr

Dictamen № 15759 (Contraloría General de la República 02 de mayo de 2017). Recuperado de https://bit.ly/34zNX3W

Dictamen No 16511 (Contraloría General de la República 27 de febrero de 2015). Recuperado de https://bit.ly/3iFyAvO

Dictamen № 17578 (Contraloría General de la República 19 de abril de 2007). Recuperado de https://bit.ly/30LOr5L

Dictamen No 18850 (Contraloría General de la República 24 de mayo de 2017). Recuperado de https://bit.ly/33ln0vz

Dictamen № 19383 (Contraloría General de la República 25 de mayo de 2001). Recuperado de https://bit.ly/2Gq9owj

Dictamen № 19940 (Contraloría General de la República 28 de abril de 2006). Recuperado de https://bit.ly/3jRaD50

Dictamen № 20108 (Contraloría General de la República 9 de junio de 1994). Recuperado de https://bit.ly/3jHUWOr

Dictamen № 21763 (Contraloría General de la República 03 de mayo de 2004). Recuperado de https://vlex.cl id: 238956154

Dictamen № 24056 (Contraloría General de la República 23 de mayo de 2008). Recuperado de https://bit.ly/3iGea5M

Dictamen № 28226 (Contraloría General de la República 16 de agosto de 1994). Recuperado de https://bit.ly/2GGf8Se 
Dictamen № 28925 (Contraloría General de la República 20 de junio de 2006). Recuperado de https://bit.ly/3llbcp1

Dictamen № 34313 (Contraloría General de la República 15 de diciembre de 1993). Recuperado de https://bit.ly/36G6j5F

Dictamen № 36106 (Contraloría General de la República 8 de julio de 2009). Recuperado de https://bit.ly/3jFTD2z

Dictamen № 39562 (Contraloría General de la República 1 de diciembre de 1997). Recuperado de https://vlex.cl id: 239258266

Dictamen № 42380 (Contraloría General de la República 17 de julio de 2012). Recuperado de https://bit.ly/3Injuwt

Dictamen № 50239 (Contraloría General de la República 8 de agosto de 2013). Recuperado de https://bit.ly/2Grle8h

Dictamen № 55344 (Contraloría General de la República 21 de noviembre de 2006). Recuperado de https://bit.ly/2I7UICp

Dictamen № 61085 (Contraloría General de la República 31 de julio de 2015). Recuperado de https://bit.ly/3deOEmX

Dictamen № 78502 (Contraloría General de la República 29 de noviembre de 2013). Recuperado de https://bit.ly/3iDXfkp

Dictamen No 83983 (Contraloría General de la República 29 de octubre de 2014). Recuperado de https://bit.ly/33HYc6S

Dictamen № 89805 (Contraloría General de la República 18 de noviembre de 2014). Recuperado de https://bit.ly/34RvQ9R

Edermira Rapiman Pichunlaf con Dirección Regional del Trabajo, Rol № 263-2011 (Corte de Apelaciones de San Miguel 6 de octubre de 2011). Recuperado de https://bit.ly/36AB4Jr

Empresa de los Ferrocarriles del Estado con Corvalán Morales y Otro, Rol № 85392009. (Corte Suprema 16 de enero de 2012). Recuperado de https://bit.ly/3d1MgA0

Evans de la Cuadra, E. (1999). Los derechos constitucionales (3a ed., Vol. 2). Santiago: Jurídica de Chile.

Gamonal Contreras, S. (1998). Derecho colectivo del trabajo en el sector público. Revista Laboral Chilena, (7), 79-85.

Gamonal Contreras, S. (2011). Trabajo y derecho (2a ed.). Santiago: Legal Publishing. 
Empresas del Estado y su vinculación al Derecho Público Chileno en materia laboral.

Gamonal Contreras, S. (2013). El derecho de huelga en la Constitución Chilena. Revista de derecho (Coquimbo), 20(1), 105-127. doi: 10.4067/s0718-

97532013000100005

García Costa, F. M. (2011). Delimitación conceptual del principio de objetividad: Objetividad, neutralidad e imparcialidad. Revista documentación administrativa, 289, 2142. Recuperado de https://bit.ly/3iUD1DH

García Pino, G., y Contreras Vásquez, P. (2014). Diccionario constitucional chileno (Vol. 55). Santiago: Cuadernos del Tribunal Constitucional. Recuperado de https://bit.ly/3mloltK

Garrido Falla, F., Palomar Olmeda, A., y Losada González, H. (2010). Tratado de derecho administrativo (15a ed., Vol. 1). Madrid: Tecnos.

Hernáez Casas-Cordero, X. (2017). Efectos de la huelga en las remuneraciones de los funcionarios públicos en Chile. Revista de derecho laboral y seguridad social, 5(2), 71 102.

Ley $N^{\circ}$ 9.618. Fija como propiedad del Estado todos los yacimientos petrolíferos que se encuentren en el territorio nacional. Diario Oficial de la República de Chile, Santiago, Chile, 19 de junio de 1950. Recuperado de http://bcn.cl/2luhv

Ley $\mathrm{N}^{\circ}$ 18.196. Normas complementarias de administración financiera, personal y de incidencia presupuestaria. Diario Oficial de la República de Chile, Santiago, Chile, 29 de diciembre de 1982. Recuperado de http://bcn.cl/2ll1 m

Ley $N^{\circ}$ 18.296. Ley Orgánica de los astilleros y maestranzas de la Armada. Diario Oficial de la República de Chile, Santiago, Chile, 07 de febrero de 1984. Recuperado de http://bcn.cl/2k3ma

Ley $N^{\circ}$ 18.297. Ley orgánica de la empresa nacional de aeronáutica de Chile. Diario Oficial de la República de Chile, Santiago, Chile, 16 de marzo de 1984. Recuperado de http://bcn.cl/2k3my

Ley $\mathrm{N}^{\circ}$ 18.382. Normas complementarias de administración financiera, personal y de incidencia presupuestaria. Diario Oficial de la República de Chile, Santiago, Chile, 28 de diciembre de 1984. Recuperado de http://bcn.cl/2ll1q

Ley $\mathrm{N}^{\circ}$ 18.575. Ley Orgánica Constitucional de bases generales de la administración del Estado. Diario Oficial de la República de Chile, Santiago, 05 de diciembre de 1986. Recuperado de http://bcn.cl/2felc

Ley N ${ }^{\circ}$ 18.834. Aprueba Estatuto Administrativo. Diario Oficial de la República de Chile, Santiago, Chile, 23 de septiembre de 1989. Recuperado de http://bcn.cl/2l5p8 
Ley N 19.132. Crea Empresa Televisión Nacional de Chile. Diario Oficial de la República de Chile, Santiago, 08 de abril 1992. Recuperado de http://bcn.cl/2lkf9

Ley $N^{\circ}$ 19.279. Autoriza negociación colectiva en empresa que señala. Diario Oficial de la República de Chile, Santiago, Chile, 18 de diciembre 1993. Recuperado de http://bcn.cl/2IIly

Ley $N^{\circ}$ 19.296. Establece normas sobre Asociaciones de Funcionarios de la Administración del Estado. Diario Oficial de la República de Chile, Santiago, Chile, 14 de marzo de 1994. Recuperado de http://bcn.cl/2k2an

Ley $\mathrm{N}^{\circ}$ 19.542. Moderniza el sector portuario estatal. Diario Oficial de la República de Chile, Santiago, Chile, 19 de diciembre de 1997. Recuperado de http://bcn.cl/2faje

Lizama Portal, L. (2005). Derecho del trabajo. Santiago: LexisNexis.

Lorena Montero Lueyza con Fisco de Chile, Rol No 4908-2019 (Corte Suprema 13 de junio de 2019). Recuperado de https://bit.ly/3IIConG

Marín Vallejo, U. (2000). Estatuto administrativo: ¿régimen en retirada en la administración pública chilena? En R. Pantoja Bauzá (Coord.), La administración del Estado de Chile (pp. 201-255). Santiago: Jurídica de Chile.

Martín-Retortillo, S. (1988). Derecho administrativo económico. Madrid: La Ley.

Morales Espinoza, B. (2008). Derechos colectivos de los funcionarios públicos del Estado administrador. En XXXVIII jornadas de derecho público: derecho público en el siglo XXI: reforma y modernización del Estado (Vol. 2, pp. 579-588). Concepción, Chile: Universidad de Concepción.

Ordinario $\mathrm{N}^{\circ} 2613$. Solicita modificar la reajustabilidad de remuneraciones de ejecutivos superiores en empresas y sociedad en que el Estado o sus instituciones tienen una participación de capital igual o superior al 50\%. Ministerio de Hacienda, Gobierno de Chile, Santiago, Chile, 09 de octubre de 2015. Recuperado de https://bit.ly/3jO4jMr

Ordinario $\mathrm{N}^{\circ} 2854$. La oportunidad para observar que una empresa se encuentra en la situación descrita en el inciso $3^{\circ}$ del artículo 304 del Código del Trabajo, es durante el proceso de negociación colectiva, específicamente en el trámite de respuesta al proyecto respectivo, establecido en el artículo 329 del mismo cuerpo legal, planteamiento que debe ser resuelto por la autoridad competente, vale decir, el Inspector del Trabajo o el Director del Trabajo, en su caso, al momento de resolver las objeciones de legalidad interpuestas por la comisión negociadora de los trabajadores. Dirección de Trabajo, Ministerio del Trabajo y Previsión Social, Gobierno de Chile, Santiago, Chile, 30 de julio de 2014. Recuperado de https://bit.ly/3lxN8iH 
Ordinario $N^{\circ} 3069 / 0153$. 1.-La oportunidad para plantear la observación que una empresa se encuentra en la situación descrita en el inciso $3^{\circ}$ del artículo 304, del Código del Trabajo, es durante el proceso de negociación colectiva, específicamente en el trámite de la respuesta, establecido en el artículo 329 del mismo cuerpo legal, planteamiento que debe ser resuelto por la autoridad competente, Inspector del Trabajo o Director del Trabajo, en su caso, al resolver las objeciones de legalidad interpuestas por la comisión negociadora de los trabajadores. 2.-Reconsidérase toda doctrina que sea contraria o incompatible con la expuesta en el presente dictamen. Dirección de Trabajo, Ministerio del Trabajo y Previsión Social, Gobierno de Chile, Santiago, Chile, 14 de agosto de 2001. Recuperado de https://bit.ly/3nGbWaq

Ordinario $\mathrm{N}^{\circ} 3356 / 50$. Fija el sentido y alcance que debe darse a la norma del inciso $3^{\circ}$ del artículo 304 del Código del Trabajo, solo en cuanto dice relación con la prohibición de negociar colectivamente allí contemplada, tratándose de las empresas o instituciones públicas o privadas cuyos presupuestos, en cualquiera de los dos últimos años, hayan sido financiados en más de un 50\% directamente por el Estado. Dirección de Trabajo, Ministerio del Trabajo y Previsión Social, Gobierno de Chile, Santiago, Chile, 01 de septiembre de 2014. Recuperado de https://bit.ly/33KxQ44

Morgan Argandoña, Guillermo y otro con Empresa de los Ferrocarriles del Estado, Rol No 13823-2014 (Corte Suprema 16 de abril de 2015). Recuperado de https://westlawchile.cl id: CL/JUR/2055/2015

Ortega Álvarez, L. (1983). Los derechos sindicales de los funcionarios públicos. Madrid: Tecnos.

Pacto Internacional de Derechos Económicos, Sociales y Culturales. Oficina del Alto Comisionado, Derecho Humanos, Naciones Unidas, 03 de enero 1967. Recuperado de https://bit.ly/3lzz6xe

Pantoja Bauzá, R. (2000). Estatuto administrativo interpretado (6a ed., Vol. 1). Santiago: Jurídica de Chile.

Precht Pizarro, J. (1989). Valor jurídico de las directivas presidenciales, programas ministeriales, circulares e instrucciones de servicio. Revista chilena de derecho, 16(2), 465-474. Recuperado de https://bit.ly/3mSv2cH

Requerimiento de 10 Senadores de la República en contra de la constitucionalidad de determinados artículos del proyecto de ley que establece la Ley General de Educación (LEGE), Rol N¹361-2009 (Tribunal Constitucional 13 de mayo de 2009). Recuperado de https://bit.ly/30EIBTB

Requerimiento para que se declare la inhabilidad para el cargo del Ministro del Interior, don Sergio Onofre Jarpa Reyes, deducido por Fabiola Letelier y otros, Rol № 191983 (Tribunal Constitucional, 13 de septiembre de 1983). Recuperado de https://bit.ly/2StrcZG 
Resolución Exenta $N^{\circ}$ 173. Califica y determina las empresas o corporaciones cuyos trabajadores no podrán ejercer el derecho a huelga, conforme a lo dispuesto por el artículo 362 del Código del Trabajo. Diario Oficial de la República de Chile, Santiago, Chile, 29 de agosto 2019. Recuperado de http://bcn.cl/2luij

Rivero Ysern, E. (1978). Derecho público y derecho privado en la organización y actividad de las empresas públicas. Revista de administración pública, (86), 11-52. Recuperado de https://bit.ly/307wzSC

Román Cordero, C. (2018). Paralizaciones/Huelgas de los funcionarios públicos. Revista de derecho público, (Especial), 59-74. Recuperado de https://bit.ly/33W3r1M

Santa María Pastor, J. A. (2004). Principios de derecho administrativo general. Madrid: lustel.

Silva Bascuñán, A. (1997). Tratado de derecho constitucional (2a ed., Vol. 4). Santiago: Jurídica de Chile.

Silva Bascuñán, A. (2010). Tratado de derecho constitucional (Vol. 13). Santiago: Jurídica de Chile.

Silva Cimma, E., y Verdugo Lay, A. (1993). Derecho administrativo chileno y comparado: La función pública. Santiago: Jurídica de Chile.

Silva Cimma, E., y Verdugo Lay, A. (1995). Derecho administrativo chileno y comparado: El servicio público. Santiago: Jurídica de Chile.

Silva Cimma, E., y Verdugo Lay, A. (1996). Derecho administrativo chileno y comparado: Introducción y fuentes (4a ed.). Santiago: Jurídica de Chile.

Sindicato de Trabajadores Industriales Sewell y mina 8 de Codelco Chile división EI Teniente y otros con Presidente de la Corporación Nacional del Cobre, Rol N²03081992 (Corte Suprema 26 de enero de 1993). Recuperado de https://westlawchile.cl id: CL/JUR/997/1993

Soto Kloss, E. (2010). Derecho administrativo: temas fundamentales (2a ed.). Santiago: Legal Publishing.

Squella Narducci, A. (2000). Introducción al derecho. Santiago: Jurídica de Chile.

Tapia Guerrero, F. J. (2006). Sindicatos: En el derecho chileno del trabajo. Santiago: LexisNexis.

Televisión Nacional de Chile con Contraloría General de la República, Rol N 1697-94. (Corte de Apelaciones de Santiago 18 de julio de 1994). Recuperado de https://westlawchile.cl id: CL/JUR/178/1994 
Empresas del Estado y su vinculación al Derecho Público Chileno en materia laboral.

Thayer Arteaga, W., y Novoa Fuenzalida, P. (2003). Manual de derecho del trabajo (4a ed., Vol. 3). Santiago: Jurídica de Chile.

Troncoso Reigada, A. (1997). Privatización, empresa pública y Constitución. Madrid: Marcial Pons.

Tudesca con Fisco, Rol No 14804-18 (Corte Suprema 11 de julio de 2019). Recuperado de https://bit.ly/30GcT8D

Ugarte Cataldo, J. L., Varas Marchant., K. y Aravena Araneda, J. (2016). Huelga y derecho. Santiago: Legal Publishing.

Valdés Prieto, D. (2006). Libre competencia y monopolio. Santiago: Jurídica de Chile.

Varas Marchant, K. (2015). La huelga en la función pública. Revista laboral chile$n a,(240), 56-63$.

Zavala Ortiz, J. L. y Morales Godoy, J. (2004). Derecho económico (2a ed.). Santiago: LexisNexis.

Zúñiga Urbina, F. (2015). La huelga como hecho social y como derecho fundamental. Revista de Derecho de la Universidad Finis Terrae, 3(1), 159-182.

\section{Para citar este artículo bajo Norma APA 6a ed. \\ Opazo de la Fuente, V. (2020). Empresas del Estado y su vincu- lación al Derecho Público Chileno en materia laboral. Revista

de derecho (Coquimbo. En línea), 27, e3331,

https://doi.org/10.22199/issn.0718-9753-2020-0017 